\title{
The Dynamic Effects of the ECB's Asset Purchases: a Survey-Based Identification
}

\author{
Stéphane Lhuissier ${ }^{1}$, Benoît Nguyen ${ }^{2}$
}

February 2021, WP \#806

\begin{abstract}
This paper estimates the dynamic effects of the ECB's asset purchase programme (APP) using a proxy structural vector autoregression. We construct a novel proxy for structural APP shocks as unexpected changes in the size of additional purchases announced by the ECB. Unexpected changes are inferred from public expectations released in quantitative surveys just before monetary policy announcements. The results consistently show that innovations to APP have expansionary effects on both output and prices: an immediate increase in asset purchases of one percent of GDP leads to a maximum impact in industrial production and consumer prices by 0.15 percent and 0.06 percent, respectively. Overall, APP shocks account for less than a fifth of the long-run macroeconomic variability. Finally, our counterfactual analyses indicate that APP and its successive recalibrations were central in supporting inflation. For example, we find inflation would have fallen into negative territory without December 2015 and March 2016 APP recalibrations.
\end{abstract}

Keywords: Monetary Policy, Asset Purchase Programme, Proxy-SVAR, Eurosystem, ECB, QE. JEL classification: E31, E32, E44, E52

\footnotetext{
The views expressed in this paper are those of the authors and should not be interpreted as reflecting the views of the Banque de France or the Eurosystem. This document is available on publications.banque-
}

\section{france.fr/en}

\footnotetext{
${ }^{1}$ Stéphane Lhuissier : Banque de France (email: stephane.lhuissier@banque-france.fr, website : http://www.stephanelhuissier.eu)).

${ }^{2}$ Benoit Nguyen : Banque de France (email: benoit.nguyen@banque-france.fr, website: https://benoitnguyen.github.io).

We would like to thank Filippo Ferroni (Banque de France discussant), Barbara Rossi, seminar participants at CFE-CM Statistics 2019 and Banque de France 2020 for valuable feedback and suggestions; Ross Finley, Sarmista Sen and the Reuters polling unit, Josh Robinson and the Bloomberg polling unit for helping us with survey data; Roberto De Santis for sharing his excess bond premium data; Nassira Abbas and the Banque de France market monitoring unit.
} 


\section{NON-TECHNICAL SUMMARY}

Quantitative easing has been since 2008 a major unconventional monetary policy tool in a context of policy rates near the effective lower bound. In the euro area, the European Central Bank (ECB) 3 launched its extended Asset Purchase Programme (APP) in January 2015, to address the mounting risks of a prolonged period of low inflation. The APP has been the main factor driving the expansion of the balance sheet of the ECB. In February 2020, the amount of securities held for monetary policy purposes by the ECB accounted for about Eur 2,700 billion -- approximately $25 \%$ of the euro area nominal GDP.

While a large literature has studied the financial market responses to asset purchases, relatively less work has assessed the response of aggregate measures of economic activity and prices, the ultimate variables of interest to the policymakers. Measuring these macroeconomic effects is challenging for at least two reasons. One is the likelihood of endogenous movements in policy variables: decisions to increase asset purchases can be responses to asset prices, inflation or other macroeconomic variables. As such, disentangling the effects of APP policy changes from the effects of non-policy factors remains inherently difficult. The second difficulty in making inference is that the ECB announcements of purchases have been partly anticipated by the public. As a result, the APP announcements are likely to be already -- even partially -- priced-in. Ensuring that the public's expectations are properly taken into account is therefore crucial to isolate changes in APP that are strictly unanticipated to assess their dynamic effects on aggregate activity.

To address these difficulties, in this paper we propose a structural vector auto-regression (SVAR) framework in which structural APP shocks are identified with an external instrument. In this class of models, commonly known as a Proxy-SVAR, the endogeneity problem is addressed by making the key assumption that the instrument is correlated with APP shocks but orthogonal to other structural shocks.

To identify APP shocks, we propose a novel instrument that relies on information released in quantitative surveys conducted with market participants by Bloomberg and Reuters ahead of each ECB Governing Council. Since late 2014, these surveys include questions over market participants' expectations on the future course of APP, and especially on the amount of additional asset purchases (if any) announced by the upcoming Governing Council.

We compute a surprise measure that serves as a proxy within a Proxy-SVAR framework to trace out the dynamic macroeconomic effects of APP. In our baseline specification, we find that APP policy has expansionary and relatively rapid effects on economic activity and prices. Specifically, we find out that an immediate increase in asset purchases of one percent of GDP leads to a maximum impact in industrial production and consumer prices by 0.15 percent and 0.06 percent, respectively. We then run a number of counterfactual exercises. We ask what would have happened if ECB had not announced and implemented major APP recalibrations. Our simulations show that each major phase of recalibration has been successful in boosting both output and prices and instrumental in preventing inflation to fall into negative territory.

\footnotetext{
${ }^{3}$ In the following we use indistinctly ECB and Eurosystem (ECB + national central banks), while in practice the Eurosystem is in charge of APP in a decentralized manner
} 
Figure: Impact of an APP shock equivalent to 1\% of GDP
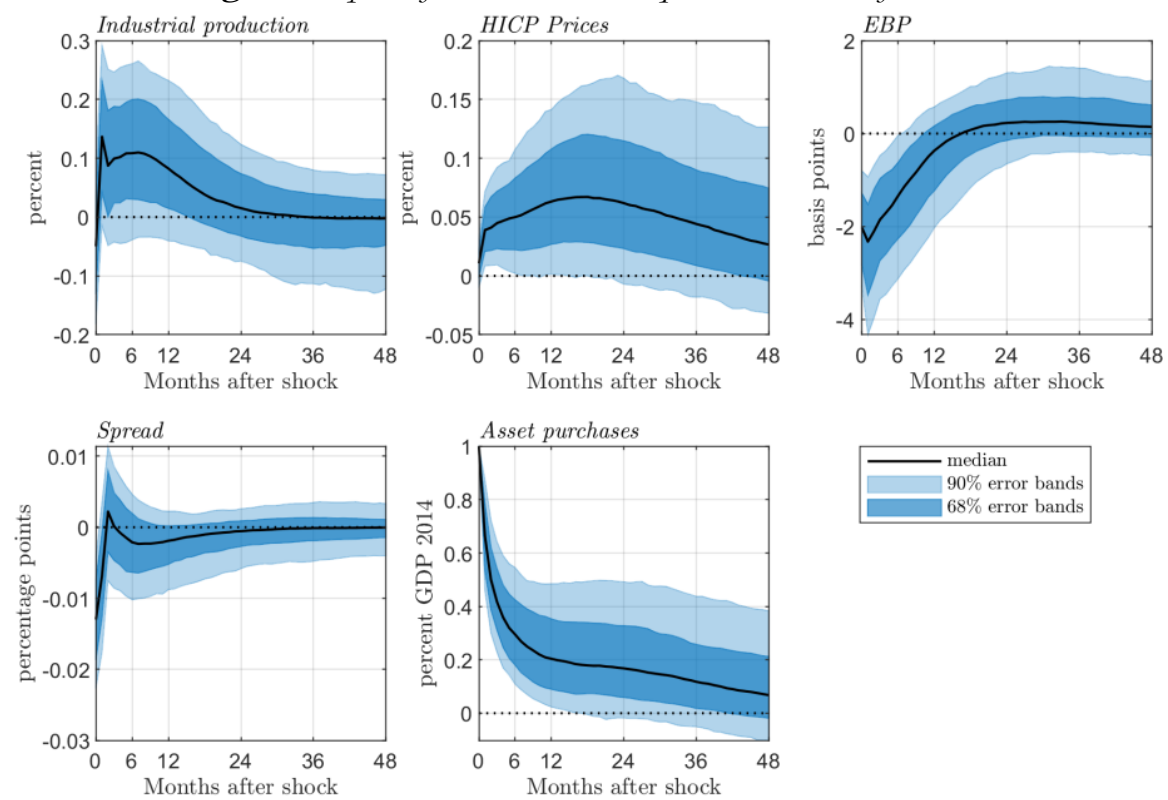

Note: The size of the asset purchases shock is scaled to induce an immediate increase in asset purchases of $1 \%$ of GDP. In each panel, the median is reported in solid line, while the 68\% and 90\% error bands are shown by blue areas. Spread is the difference between the 4 largest Euro area countries (DE, FR, IT, ES) GDP-weighted 10-year government bond yields and the 10-year overnight index swaps (OIS). EBP stands for Excess Bond premium.

\title{
L'impact dynamique des achats de titre de la BCE : une stratégie d'identification tirée des anticipations de marché
}

\begin{abstract}
RÉSUMÉ
Nous estimons l'effet dynamique du programme d'achat de titres de l'Eurosystème (APP) dans le cadre d'un vecteur autorégressif structurel avec instrumente externe. Nous construisons un proxy des chocs structurels d'APP reflétant les changements non-anticipés des achats supplémentaires annoncés par la BCE. Ceux-ci sont déduits des anticipations de marché tirées de sondages réalisés juste avant les annonces de politique monétaire. Nos résultats montrent de manière robuste que les innovations d'APP ont un effet expansionniste sur les prix et sur l'activité. Une hausse immédiate des achats d'actifs de l'ordre de $1 \%$ du PIB entraîne un impact maximum sur la production industrielle et sur les prix à la consommation de $0.15 \%$ et $0.06 \%$, respectivement. Au total, les chocs d'APP comptent pour un cinquième de la variance macroéconomique de long-terme. Enfin, nos analyses contrefactuelles suggèrent que l'APP et ses recalibrages successifs ont été centraux pour soutenir l'inflation en zone euro: celle-ci aurait par exemple connu des épisodes de déflation en l'absence des mesures d'APP de décembre 2015 et mars 2016.
\end{abstract}

Mots-clés : Politique monétaire, Programme d'achat d'actifs, Proxy-SVAR, Eurosystème, BCE, QE. 


\section{INTRODUCTION}

Quantitative easing has been since 2008 a major unconventional monetary policy tool in a context of policy rates near the effective lower bound. In the euro area, the European Central Bank (ECB) ${ }^{1}$ launched its extended Asset Purchase Programme (APP) in January 2015, to address the mounting risks of a prolonged period of low inflation. As shown in Figure 1, the APP has been the main factor driving the expansion of the balance sheet of the ECB. In February 2020, the amount of securities held for monetary policy purposes by the ECB accounted for about Eur 2,700 billion - approximately 25\% of the euro area nominal Gross Domestic Product (GDP).

While a large literature has studied the financial market responses to asset purchases, relatively less work has assessed the response of aggregate measures of economic activity and prices, the ultimate variables of interest to the policymakers. Measuring these macroeconomic effects is challenging for, at least, two reasons. One is the likelihood of endogenous movements in policy variables. Central bankers collect and analyze a large set of economic information on which they base their assessment. As a result, asset purchases decisions are responses to information about changes in asset prices, inflation, and others macroeconomic variables. As such, disentangling the effects of APP policy changes from the effects of non-policy factors remains inherently difficult. The second difficulty in making inference is that the ECB announcements of purchases have been partly anticipated by the public. Market participants build expectations on financial and macroeconomic variables, and adjust in anticipation of economic change and thus of monetary policy actions. As a result, the APP announcements are likely to be already - even partially - priced-in. Ensuring that the public's expectations are properly taken into account is therefore crucial to isolate changes in APP that are strictly unanticipated to assess their dynamic effects on aggregate activity.

To address these difficulties, in this paper we propose a structural vector autoregression (SVAR) framework in which structural APP shocks are identified with an external instrument (i.e., proxy) along the lines of Stock and Watson (2012) and Mertens and Ravn (2013). In this class of models, commonly known as a Proxy-SVAR, the endogeneity problem is addressed by making the key assumption that the instrument is correlated with APP shocks but orthogonal to other structural shocks. To identify APP shocks, we propose a novel instrument which relies on information from quantitative surveys conducted with market participants by Bloomberg and Reuters ahead of each ECB Governing Council. Since late 2014, these surveys include questions over market participants' expectations on the future course of APP,

\footnotetext{
${ }^{1}$ In the following we use indistinctly ECB and Eurosystem (ECB + national central banks), while in practice the Eurosystem is in charge of APP in a decentralized manner.
} 
and especially on the amount of additional asset purchases (if any) announced by the upcoming Governing Council. For each APP announcement and recalibration, we compute the difference between the median additional amount expected by market participants, and the additional amount officially announced by the ECB. By doing so, the resulting series of APP surprises should be relatively free of anticipatory actions.

We then use our surprise measure as a proxy within a Proxy-SVAR framework to trace out the dynamic effects of APP on aggregate activity. In our baseline specification, we find that APP policy has expansionary and relatively rapid effects on economic activity and prices. Specifically, we find out that an immediate increase in asset purchases of one percent of GDP leads to a maximum impact in industrial production and consumer prices by 0.15 percent and 0.06 percent, respectively. The contribution of these shocks to macroeconomic variability appear modest but non-negligible. They account for about less than a fifth of variability in long-run output and consumer prices. The minor historical role for APP policy in generating business cycle fluctuations is quantitatively similar to the ones typically found in the literature on the effects of conventional monetary policy (e.g., Leeper, Sims, and Zha, 1996; Peersman and Smets, 2003), and results mainly from the fact that much of the observed variations in asset purchases is systematically responsive to the state of the economy, which is what one would expect from a good monetary policy.

Since ECB actions, via asset purchases, have historically been systematic reactions to the state of the economy, we run a number of counterfactual exercises to assess the effects of the systematic component of asset purchases, as opposed to the effects of the unpredictable component of policy. Specifically, we ask what would have happened if ECB would have not announced and implemented major APP recalibrations (December 2015 \& March 2016, December 2016, October 2017 \& March 2018, and September 2019). To do so, we run counterfactual simulations with alternate time series of APP shocks so that asset purchases are completely unresponsive to other variables in the system. Our simulations show that each major phase of recalibration has been successful in boosting both output and prices and instrumental in preventing inflation to fall into negative territory. Since we are potentially ignoring changes in the dynamics of the private sector that would occur as a policy intervention induces agents to update their beliefs about policy (the Lucas critique), we test if our counterfactual simulations can be viewed as "modest" in the sense of Leeper and Zha (2003), which would imply that economic agents do not revise their expectations and simulations are plausible. Evidence clearly suggests that this is indeed the case.

The paper is organised as follows. Section II relates our contribution to the literature. Section III provides details about the ECB's asset purchase programme. Section IV discusses the identification via external instruments in the Proxy-SVAR framework. Section V 
introduces the construction of the proxy for APP shocks used to identify the VAR model. Section VI presents the main results. Section VII conducts several counterfactual exercises to assess the role of APP as a source of business cycle fluctuations. Section VIII concludes.

\section{Literature REVIEW}

Much of the existing empirical literature on the effects of central banks' asset purchases has focused on the impact on financial variables. There is a large consensus on the efficacy of asset purchases to lower long-term rates, for instance, yet surrounded with a large uncertainty and often silent about the transmission to the macroeconomic variables and the persistence of this effect. In comparison, while central in the unconventional monetary policy toolkit for the past ten years, the empirical literature has been relatively scarcer on asset purchases' macroeconomic impact. ${ }^{2}$

A first strand of the literature relies on a two-step approach: an event-study, typically conducted at high frequency ${ }^{3}$, is first used to estimate the impact of policy interventions on a financial variable (typically a long-term rate), then plugged in an estimated macroeconomic model to derive their impact on prices and output. Examples of this approach include for instance Chung, Laforte, Reifschneider, and Williams (2011), Baumeister and Benati (2013) and Liu, Theodoridis, Mumtaz, and Zanetti (2019) in the U.S., and Altavilla, Giannone, and Lenza (2016), Lhuissier (2017) and Rostagno, Altavilla, Carboni, Lemke, Motto, Saint Guilhem, and Yiangou (2019) in the context of the euro area. This strategy crucially relies for the identification on the interpretation of high frequency changes in the price of market instruments around policy announcements, which can raise its own questions (see, for instance, Wright (2019) on the identification of APP, Andrade and Ferroni (2020) and Miranda-Agrippino and Ricco (forthcoming) on whether these changes are really unpredictable, and Swanson (2020) on the interpretation of high frequency surprises).

A second strand of the literature aims at directly identifying APP shocks in variables incorporated in VAR models, such as a realized or announced central bank balance sheet variable to isolate asset purchases. This includes for instance Gambacorta, Hofmann, and Peersman (2014), Weale and Wieladek (2016), Garcia Pascual and Wieladek (2016), Boeckx, Dossche, and Peersman (2017) and Gambetti and Musso (2020). In these papers, the approach to identify balance sheet shocks is based on a mixture of zero and sign restrictions. The harshest critics of identified VARs would claim that such assumptions are not sufficient,

\footnotetext{
${ }^{2}$ See Hartmann and Smets (2018), Pfister and Sahuc (2020) and Rossi (2020) for instance for a review.

${ }^{3}$ Building in particular on the methodology developed first in the U.S. by Gürkaynak, Sack, and Swanson (2005) and Swanson (2020), and adapted by Altavilla, Brugnolini, Gürkaynak, Motto, and Ragusa (2019) for the euro area.
} 
or even unrealistic, to identify pure structural shocks. ${ }^{4}$ There are two main reasons. First, the Uhlig (2005)'s critique points out a questionable immediate zero restriction on impulse responses of aggregate activity to a monetary policy shock. There is no reason to believe that economic activity does not react, within month, to any shocks hitting the economy, including those originating from financial and monetary markets. Within-month effects of monetary policy on output and prices are probably fairly small, but that does not make them literally zero. Second, the method of sign restrictions needs strong theoretical priors. Most of studies impose an ease in financial conditions following expansionary policy shocks whereas they might have an indiscernible or even counter-intuitive impact on key financial variables - for instance the 10-year U.S. Treasury yield went up just after the announcement of the Federal Reserve's second round of quantitative easing in November $2010 .^{5}$ Overall, a set of inadequate restrictions may fail to separate the systematic response of policy to the economy from the response of the economy to policy, thus producing an inaccurate measure of the effects of policy changes.

By contrast, our Proxy-VAR approach requires less structural assumptions since the identification scheme is based on an external instrument without pre-imposing assumptions on the immediate impact of the shock on the economy. We construct our proxy variable using information from quantitative surveys in which market participants are asked about their expectations of policy change at the upcoming ECB monetary policy meeting in terms of additional purchases to be announced. Furthermore, our approach allows to explicitly account for possible measurement errors in the construction of the proxy for APP shocks - a feature that is particularly well-suited given (i) many observations are censored to zero, and (ii) the number limited of respondents in quantitative surveys. To the best of our knowledge, our paper is the first one to identify asset purchases surprises using market participants' expectations directly as a proxy in a structural VAR. We show our method is robust to using different market expectations sources, and consistent with accounts of each decision by the financial press.

From a methodological standpoint, our paper is related to an increasing literature using external instruments to identify structural shocks within a VAR framework. Stock and Watson (2012) and Mertens and Ravn (2013) have pioneered the development of this methodology

\footnotetext{
${ }^{4}$ Note also that there is recent debate on whether SVARs with sign restrictions are really able to identify unconventional monetary policy shocks. See Elbourne and Ji (2019) and Boeckx, Dossche, Galesi, Hofmann, and Peersman (2019).

${ }^{5}$ For example, Gambacorta, Hofmann, and Peersman (2014) identify balance sheet shocks by assuming that an expansionary monetary policy shock leads to an immediate rise in the balance sheet of the ECB and an immediate fall in the ECB's Composite Indicator of Systematic Stress (CISS).
} 
using a frequentist approach, while Caldara and Herbst (2019), Drautzburg (forthcoming), and Arias, Rubio-Ramírez, and Waggoner (2018) have introduced Bayesian inference. Studies have used the methodology to assess the effects of conventional and unconventional monetary policy measures: notable examples include Gertler and Karadi (2015), Li and Zanetti (2016), Jarociński and Karadi (2020), Lhuissier and Szczerbowicz (2018), and Caldara and Herbst (2019). Kim, Laubach, and Wei (2020) deploy a strategy closer to our benchmark specification; the authors estimate the macroeconomic effects of Federal Reserve's large scale asset purchases (LSAP) using a structural VAR with external instruments. One major difference with our approach is that their external instrument is a "LSAP" factor computed from a set of high frequency asset price changes surrounding monetary policy announcements.

\section{INSTITUTIONAL DETAILS}

The extended APP was announced on January, 22 2015, for an initial size of Eur 1140 billion. The programme consisted for the first time in large scale purchases of public securities $^{6}$, which completed the existing smaller scale purchases of covered bonds (CBPP) and ABS (ABSPP). In March 2016, the ECB added a programme on corporate bonds (CSPP) consisting in the purchase of investment-grade (rated higher than BBB-) bonds issued by non-financial companies.

The APP has been re-calibrated several times in terms of pace and length of purchases. The initial announcement in January 2015 has been followed by 6 recalibrations during our period under review, see Table 1. The first recalibration was announced in December 2015, as a 6 months extension from the initial ending date (September 2016) to the end of March 2017. In March 2016 the monthly pace of purchases was increased from 60 to 80 billion starting from April 2016 - with an unchanged ending date in March 2017. In December 2016, the Governing council announced a 9-month extension to December 2017 at 60 billion per month. In October 2017 APP purchases were extended until September 2018 at a lower monthly pace of 30 billion. In June 2018, the ECB added 3 additional months at Eur 15 billion per month until the end-December 2018. Finally, in September 2019, the Governing council restarted the APP purchases, from November 2019 at Eur 20 billion per month.

While net purchases have stopped between December 2018 and November 2019, the securities purchased by the Eurosystem under its various sub-APP programmes are meant to be held until maturity and redemptions in the monetary policy portfolio are reinvested for an horizon linked by the ECB to the next policy rate hike - which explains why the ECB balance sheet did not shrink since 2015. In February 2020 - before the Covid-19 crisis

\footnotetext{
${ }^{6}$ Prior to the extended APP, the ECB ran several smaller-scale purchase programmes, on peripheral debts (SMP 2010-2011) and on specific market segments (covered bonds and ABS).
} 
triggered additional emergency stimulus - the amount of securities held by the Eurosystem accounted for Eur 2,700 billion, or around 25\% of the euro area nominal GDP.

The purchases are intended to be implemented in a market neutral way, meaning their are conducted in proportion of the market outstanding (See Hammermann, Leonard, Nardelli, and von Landesberger (2019)). This means, notably, that the weighted average maturity (WAM) of the APP portfolio closely follows the WAM of the market, which can be verified each month on the ECB website. ${ }^{7}$ In addition, set aside one technical change in the eligibility criteria (eg. bond residual maturity lowered to 1 year instead of 2 years in Dec 2016), there has been no change in the maturity composition of purchases. As a result, the WAM of the PSPP has been remarkably stable around 7 years. Put differently, by analogy to the metrics used in Eser, Lemke, Nyholm, Radde, and Vladu (2019) this means the ratio of 10-year equivalent of 100 Eur bn additional purchases scaled by 10-year equivalent of the eligible outstanding remains stable over time.

In terms of the asset composition of purchases, the share between public and private securities has been remarkably stable (around $80 \%$ in public securities). The purchases under the CSPP merely substitute to those in the small covered and ABS markets.

To sum up, for these two reasons, we think the information on the size of APP is an appropriate summary of the degree of accommodation provided by APP in the euro area, while we acknowledge this can be more complex in the U.S. for instance, where the Federal Reserve also actively used as a policy tool the maturity of asset purchases (MEP) or their relative composition between MBS and Treasuries.

\section{The PROXY-SVAR MODEL}

This section outlines the empirical approach that is used to estimate the macroeconomic impact of APP shocks in the euro area. Since the seminal paper by Sims (1980), SVAR models have been widely employed to estimate the effects of monetary policy shocks on the economy. Identified VAR modeling allows to analyze and interpret the data while avoiding potentially "incredible restrictions" on the structure of the economy. In this respect, and following the methodology established by Stock and Watson (2012) and Mertens and Ravn (2013), we propose to use an external instrument for identifying APP shocks.

We consider that the euro area economy can be described by a SVAR with the following general form

$$
\mathbf{y}_{t}^{\prime} \mathbf{A}_{0}=\sum_{\ell=1}^{p} \mathbf{y}_{t-\ell}^{\prime} \mathbf{A}_{\ell}+\mathbf{c}+\varepsilon_{t}^{\prime} \text { for } 1 \leq t \leq T
$$

\footnotetext{
${ }^{7}$ https://www.ecb.europa.eu/mopo/implement/omt/html/index.en.html\#pspp
} 
where $\mathbf{y}_{t}$ is an $n \times 1$ vector of endogenous variables, $\boldsymbol{\varepsilon}_{t}$ is an $n \times 1$ vector of exogenous structural shocks, $\mathbf{A}_{\ell}$ is an $n \times n$ matrix of parameters for $0 \leq \ell \leq p$ with $\mathbf{A}_{0}$ invertible, $\mathbf{c}$ is a $1 \times n$ vector of parameters, $p$ is the lag length, and $T$ is the sample size. The vector $\varepsilon_{t}$, conditional on past information and the initial conditions $\mathbf{y}_{0}, \ldots, \mathbf{y}_{1-p}$, is Gaussian with mean zero and covariance matrix $\mathbf{I}_{n}$, the $n \times n$ identity matrix. The model described in equation (1) can be compactly written as

$$
\mathbf{y}_{t}^{\prime} \mathbf{A}_{0}=\mathbf{x}_{t}^{\prime} \mathbf{A}_{+}+\boldsymbol{\varepsilon}_{t}^{\prime} \text { for } 1 \leq t \leq T
$$

where $\mathbf{A}_{+}^{\prime}=\left[\begin{array}{llll}\mathbf{A}_{1}^{\prime} \cdots & \mathbf{A}_{p}^{\prime} & \mathbf{c}^{\prime}\end{array}\right]$ and $\mathbf{x}_{t}^{\prime}=\left[\begin{array}{llll}\mathbf{y}_{t-1}^{\prime} & \cdots & \mathbf{y}_{t-p}^{\prime} & 1\end{array}\right]$ for $1 \leq t \leq T$. The dimension of $\mathbf{A}_{+}$is $m \times n$, where $m=n p+1$.

The reduced-form representation implied by Equation

$$
\mathbf{y}_{t}^{\prime}=\mathbf{x}_{t}^{\prime} \mathbf{B}+\mathbf{u}_{t}^{\prime} \text { for } 1 \leq t \leq T,
$$

where $\mathbf{B}=\mathbf{A}_{+} \mathbf{A}_{0}^{-1}, \mathbf{u}_{t}^{\prime}=\varepsilon_{t}^{\prime} \mathbf{A}_{0}^{-1}$, and $\mathbb{E}\left[\mathbf{u}_{t} \mathbf{u}_{t}^{\prime}\right]=\boldsymbol{\Sigma}=\left(\mathbf{A}_{0} \mathbf{A}_{0}^{\prime}\right)^{-1}$. The matrices $\mathbf{B}$ and $\boldsymbol{\Sigma}$ are the reduced-form parameters, while $\mathbf{A}_{0}$ and $\mathbf{A}_{+}$are the structural parameters. Following Rubio-Ramírez, Waggoner, and Zha (2010), the parameters $\left(\mathbf{A}_{0}, \mathbf{A}_{+}\right)$and $\left(\tilde{\mathbf{A}}_{0}, \tilde{\mathbf{A}}_{+}\right)$are observationally equivalent if and only if they have the same reduced-form representation.

In the benchmark specification, the vector of endogenous variables $\mathbf{y}_{t}$ consists of five monthly euro area variables: the logarithm of industrial production $\left(i p_{t}\right)$; the logarithm of the Harmonized Index of Consumer Prices, HICP $\left(p_{t}\right)$; the cumulative amount of asset purchases announced scaled by the annualized 2014 euro area GDP $\left(b_{t}\right)$; the De Santis (2018a,b)'s excess bond premium, EBP $\left(e b p_{t}\right)$; and the spread between the 10-year euro area government bond yields of the four largest euro area countries (Germany, France, Italy, and Spain) and the 10-year OIS rate $\left(s p_{t}\right)$.

All variables are monthly time series covering November 2014 through December 2019. Our main sources for the data are the ECB's Statistical Data Warehouse and Bloomberg. The asset purchase announcement series (Figure 2) is constructed from ECB official announcements in the Weale and Wieladek (2016)'s manner: asset purchase announcements are simply cumulated over time, i.e., it reflects the total purchases announced. Regarding our financial variables, our 10-year spread - sometimes called swap spread but the denomination bondOIS spread would be the most accurate - has been widely used by the ECB in assessing the APP (e.g., Coeuré, 2017) and is a convenient model-free way to proxy the term premium. ${ }^{8}$ It is also justified by our focus on APP: retrenching the OIS rate controls for the expected path of short term interest rates which is more directly connected to other instruments like

\footnotetext{
${ }^{8}$ Term premium can be extracted from term structure models and reflects the yield curve component remunerating the interest rate risks. A bond-OIS spread cannot capture these full risks as the OIS curve itself embeds a risk component.
} 
forward guidance. Our second financial variable is a euro area excess bond premium (De Santis, 2018a,b) computed similarly to Gilchrist and Zakrajšsek (2012). The series is the credit spread component capturing the investors' appetite for bearing corporate debt exposure, correcting from default risk. Put differently it measures the compensation investors ask to invest in corporate debt market, above the simple compensation they require for default risk. The series is computed from secondary market prices of senior unsecured bonds, purged from observable determinants at firm and bond level, like default risk, maturity, etc. Favara, Gilchrist, Lewis, and Zakrajšek (2016) shows that the excess bond premium is a good predictor of economic downturn. More details about data are presented in Appendix A.

Our Proxy-SVAR is estimated over the sample period January 2015-December 2019, so that the data allow inclusion of a two-period $\operatorname{lag}^{9}$. The SVAR specification does not include any deterministic term.

Our structural approach requires the identification of the coefficients of $\mathbf{A}_{0}^{-1}$. Since we only study the effects of unexpected APP shocks, only the coefficients of the fifth column of $\mathbf{A}_{0}^{-1}$ have to be identified. Our approach to identification of APP policy is based on the use of an external instrument, $z_{t}$, along the lines of Stock and Watson (2012) and Mertens and Ravn (2013). Both studies show how the external instrument can be used to identify structural shocks. Specifically, the identification must satisfy several critical assumptions in order to identify movements in the policy indicator that are due to purely exogenous monetary policy disturbances. In particular, the instrument must be correlated with APP shocks $\varepsilon_{t}^{p}$ but uncorrelated with all other structural shocks $\varepsilon_{t}^{\neq p}$. This assumption can be summarized as follows:

$$
\begin{aligned}
\mathrm{E}\left[z_{t} \varepsilon_{t}^{p}\right] & =\psi \\
\mathrm{E}\left[z_{t} \varepsilon_{t}^{\neq p}\right] & =0
\end{aligned}
$$

We adopt a Bayesian approach along the lines of Arias, Rubio-Ramírez, and Waggoner (2018) to estimate our Proxy-SVAR. ${ }^{10}$ The authors have developed an efficient algorithm to independently draw from the posterior distribution over the structural parameterization of a Proxy-SVAR conditional on exogeneity restrictions as shown in equations (4) and (5). For the estimation of the model, we augment the vector of endogenous variables to include the instrument, such that the dimension of $\mathbf{y}_{t}$ is now a $\tilde{n} \times 1$ matrix, with $\tilde{n}=n+1$, and we use a restricted normal-generalized-normal posterior distribution over the triangular-block

\footnotetext{
${ }^{9}$ Our dataset does not cover the COVID-19 pandemic period because of unprecedented variation in our macroeconomic variables, which in turn distorts severely parameter estimates. See, for example, Lenza and Primiceri (2020) for further details.

${ }^{10}$ The choice of a Bayesian rather than a frequentist approach is justified by the small sample size.
} 
parameters, which is characterized by four parameters; $N G N(\nu, \boldsymbol{\Phi}, \boldsymbol{\Psi}, \boldsymbol{\Omega})$. Our choice of prior density parameterization is $\nu=\tilde{n}=6, \boldsymbol{\Phi}=\mathbf{0}_{\tilde{n}, \tilde{n}}, \boldsymbol{\Psi}=\mathbf{0}_{\tilde{m} \tilde{n}, \tilde{n}}$, and $\boldsymbol{\Omega}^{-1}=\mathbf{0}_{\tilde{m} \tilde{n}, \tilde{m} \tilde{n}}$, with $\tilde{m}=\tilde{n}+1$. Such a parameterization is common in the literature and leads to prior densities that are equivalent to those in Uhlig (2005). For more details and implementation, we refer to Arias, Rubio-Ramírez, and Waggoner (2018). Below, we propose a novel instrument to identify APP shocks.

\section{A PROXY FOR APP SHOCKS}

Our proxy is the unexpected size of additional APP purchases announced by the ECB. We detail in this section our sources and methodology. To infer market expectations over the APP announcements, we rely on surveys conducted by Reuters and Bloomberg ahead of each Governing council ${ }^{11}$. These surveys include questions over the interest rate path, the size, pace and composition of APP, or the macroeconomic forecasts for the euro area. Both ask participants about their expectations of monetary policy decision at the next Governing Council. In particular, we use two types of information:

i. the likelihood of an APP announcement at the next Governing Council: e.g. "Do you expect the ECB to announce QE at its January 22 meeting?"

ii. the median amount of additional purchases to be announced, e.g. "What total do you expect the ECB to announce?"

Questions were often asked in different ways (eg. a pace + a length of purchases, or a total additional amount) but it is rather straightforward to infer the next Governing Council expectations in terms of APP. Table 2 details the sources and questions we have exploited at each date.

We use preferably the surveys conducted by Bloomberg, as they have more respondents (around 60) and are available during the whole period, while Reuters asked direct questions on APP less frequently and on a smaller sample. When the two surveys overlap, we find both are remarkably similar in terms of APP expectations. In few occasions when the Bloomberg survey is unclear or incomplete, this allows us to complement the answers with the Reuters one. For instance, in March 2016, Bloomberg reports a majority of market participants believes the ECB will "expand QE purchases above Eur 60 billion a month", while in the Reuters survey market participants were asked to give directly their expectations of monthly amount. The median was 70 billion Eur a month, which is what we use.

\footnotetext{
${ }^{11}$ In the euro area, there is no publicly-available equivalent to the Survey of primary dealers conducted by the New York Fed, used for instance by Cao and Foerster (2013) and Kim, Laubach, and Wei (2020). Both Bloomberg and Reuters surveys results are typically published three or four business days before the Governing councils.
} 
We also check the consistency of the expectations with two internal sources: a Banque de France survey (BDF) among market participants since 2017 and the ECB Survey of Monetary Analysts (SMA) conducted by the ECB since the April 2019, both confidential and conducted before each Governing Council. Both largely convey the same information and corroborate our measure from Bloomberg and Reuters surveys. In total, this allows us to cross-check our expectations measure using four independent sources.

We then compute a surprise as the difference between these expectations and the additional APP amount effectively announced by the ECB, which happened 7 times (initial announcement in January 2015 followed by 6 recalibrations). More specifically, we compute surprises as the difference at each relevant Governing Council between the median additional purchases expected and the additional purchases effectively announced by the ECB. Figure 3 shows the distribution of additional amount expectations across market participants ahead of 3 major announcement dates. Interestingly, the dispersion of expectations varies considerably: while some (small) recalibrations seems perfectly consensual (e.g. June 2018), the most important recalibrations in terms of amount take place with a larger uncertainty. In September 2019 the 25/75 percentiles of expectations lied between Eur 300 and 500 billion, with min and max between Eur 200 and 700 billion.

In all but one case during our period of interest, computing these surprises is straightforward as the ECB announced a fixed and predetermined additional amount. For instance, in December 2015, the Governing Council announced an extension of the APP by 6 months at the same pace of Eur 60 billion per month: "we decided to extend the asset purchase programme (APP). The monthly purchases of Eur 60 billion under the APP are now intended to run until the end of March 2017" (See Table 1). However, in September 2019, the ECB announced an open-ended restart of the APP: "Net purchases will be restarted under the Governing Council's asset purchase programme (APP) at a monthly pace of Eur 20 billion as from 1 November. The Governing Council expects them to run for as long as necessary to reinforce the accommodative impact of its policy rates, and to end shortly before it starts raising the key ECB interest rates." 12 . The ECB statement conveys two important indications: the APP extension is linked to the horizon of the first hike, and the net asset purchases will stop "shortly before" this happens. In the September polls, the first DFR hike was expected around mid-2022 "shortly before" was interpreted as around 3 months. In the Bloomberg poll conducted on 16-Oct-2019, at the question "The ECB says asset purchases will end "shortly" before the first rate increase. How do you define "shortly"?", the median answer was 3 months, while the first rate hike was expected around end-2022. As purchases restarted in November 2019, this means 2 months in $2019+3^{*} 12$ months (in 2020, 2021

\footnotetext{
12https://www.ecb.europa.eu/press/pr/date/2019/html/ecb.mp190912 08de50b4d2.en.html
} 
and 2022) - 3 months ("shortly before"). This implies market participants understood what ECB announced in September 2019 as around Eur 700 billion APP extension (assuming a Eur 20 billion/month pace, which is expected by virtually all the poll respondents), while they expected Eur 384 billion (See Table 2).

To cross check, we also use the OIS curve on the days just before the September 2019 Governing Council to derive the horizon of the next 10 basis points rate hike priced by the swap market. We take all Eur OIS contracts with standard maturities (3,6,9,12 months and 2 to 10 years) and build the OIS curve using the Nelson-Siegel procedure in order to obtain a precise data point at each date in the future. The OIS curve just before the September 2019 Governing Council (Figure B.1 in Appendix) suggests one or two further cuts and a first rate hike in January 2023, perfectly consistent with the survey. We also look at how much did the market participants rescale their expectations over the total size of the APP between September 19 (before the Governing Council) and October 19 (next survey) using internal sources (SMA and BDF described above). This information broadly corroborates the magnitude of our back-of-the envelope estimation.

Figure 4 shows our proxy: surprises in Eur amount scaled by the euro area nominal GDP, that we lag as of 2014 Q1 - before any discussion on APP. The value of the proxy is positive when the ECB announces a bigger extension in APP purchases than expected by the market. The average surprise is $1.9 \%$ of GDP. The first surprise in January 2015 and the last one in Sept. 2019 are by far the most important, respectively at $6.1 \%$ and $4.9 \%$.

Interestingly, there is always a large consensus of market participants on the timing according to which actual APP decisions are announced: for each of the 7 APP decisions, all have been predicted by at least $60 \%$ of respondents (and 4 by at least $80 \%$ ). Conversely, there is no example of a significant proportion of respondents expecting an APP decision at a Governing Council which turned out to be a non-event. Put differently, this excludes major negative surprises occurring because market participants expected a decision when none was taken. ${ }^{13}$ This suggests market participants have inferred correctly the timing of APP announcements, probably because most decisions are prefigured via different communication means - eg. Governing council members interviews, speeches, past Governing Council accounts, etc. Conversely, the Governing council members may also partly form their decisions with in mind the market expectations - all surveys being publicly released few days before the meeting.

Our preferred measure of surprises takes into account the fact that sometimes a proportion of respondents expected no announcement at all at the upcoming Governing Council. We set their expectations at 0 . In the robustness section, we also recompute the surprises using

\footnotetext{
${ }^{13}$ Note also that no APP decision has been made outside of a Governing Council.
} 
only the answers by the respondents who believed in an announcement at the next Governing Council (see Figure D.2 in Appendix).

Finally, to further substantiate our approach, for all our surprises we check the narrative with external sources. To ensure for instance that what we compute as negative surprises correspond to the market sentiment, we check how the ECB decision has been reported in major economic newspapers. In all cases, the sign of our surprises is corroborated by the press, as can be seen on Table 3.

One question that naturally emerges is how different from high-frequency identification are our APP surprises and whether it brings similar or complementary information. To do so, we replicate the high-frequency QE factor of Altavilla, Brugnolini, Gürkaynak, Motto, and Ragusa (2019) ${ }^{14}$, extend it until the end of 2019, and run a simple correlation analysis between our APP surprises and their QE factor. The correlation is relatively small at 0.24 , suggesting the two approaches indeed bring alternative identifications. This should not be seen as surprising, as by construction, our proxy relies on 7 surprises corresponding to announcement and recalibrations of APP by the ECB, while the high-frequency literature extracts a "QE factor" from the changes in the long-end of the OIS curve around a longer sets of events, in large part outside of key APP announcements we focus at. Extraction of factors and their interpretation allow to disentangle different types of monetary policy shocks (eg. one factor interpreted as forward guidance, another as quantitative easing, etc...) where we only focus on asset purchases. While restricted to this particular instrument and reliant on the availability of a range of repeated market surveys, the advantage of our method is to be free from this additional identification step that might raise its own questions: for instance, Wright (2019) suggests APP cannot be identifiable only from high frequency moves of the OIS curve but foremost from term premia and intra euro-area sovereign spreads.

\section{MAin Results}

This section presents the main results. First, Section VI.1 presents the time series of APP shocks. Second, Section VI.2 reports the impulse responses of APP shocks. Third, Section VI.3 assesses the quantitative importance of APP shocks through a variance decomposition. Fourth, to establish the contribution of APP shocks to business cycle fluctuations over time, Section VI.4 displays the historical decomposition. Finally, VI.5 conduct some robustness of the results.

VI.1. Identified APP Shocks. Before describing the dynamic effects of APP shocks on the economy, we provide an empirical interpretation of the evolution of these disturbances over

\footnotetext{
${ }^{14}$ Thanks to the data and code made available on Julia. Gürkaynak's website: http://refet.bilkent. edu.tr/research.html
} 
time. Figure 5 displays the time series of APP shocks from January 2015 to December 2019. The black line reports the median, while the blue areas report the $68 \%$ and $90 \%$ probability intervals. A positive value means an expansionary APP shock.

As can be seen, APP shocks capture remarkably well the dates of the introduction and recalibrations of APP, notably January 2015, December 2017 and September 2019. The largest of the historical positive APP shocks occurred in January 2015 when ECB announced the introduction of APP to further ease the monetary policy stance.

Overall, this pattern is in line with the corresponding instrument, as shown by the high correlation between the instrument and the identified shock in Figure 6. The posterior distribution of correlation, which is relatively tight, has the entire of its mass far from zero with a median value equal to 0.69 , thus reflecting the relevance of our APP instrument. ${ }^{15}$

In the spirit of Forni and Gambetti (2014), we perform a test of "structuralness" of the estimated APP shocks to verify that the VAR contains sufficient information to identify the structural APP shocks. We do so by projecting the structural APP shocks onto the factors summarizing the information content of a large set of information available ahead of each Governing Council. The results, reported in Appendix C, indicate that our structural shocks are not predictable based on past information available, and thus the structuralness is accepted. ${ }^{16}$

VI.2. Impulse Response Analysis. The macroeconomic impact of an APP shock is traced out in Figures 7. The median is reported in solid black line, and the $68 \%$ and the $90 \%$ error bands in blue areas. The size of an APP shock is scaled to induce an immediate increase in asset purchases of $1 \%$ of GDP. ${ }^{17}$

After the initial rise, asset purchases stay persistently above the level expected prior to the shock, and gradually converge to the pre-shock expected level in the longer run. Most importantly, the rise in asset purchases provide a substantial short run output and prices stimulus. Both variables immediately rise, and then begin to return to their pre-shock levels in a steady manner. The maximum impact is 0.12 percent on industrial production and 0.06 percent on prices. Furthermore, the $68 \%$ and $90 \%$ probability intervals lie mostly within the

\footnotetext{
${ }^{15}$ Following Gertler and Karadi (2015), we have also regressed the residuals of the fifth equation ("asset purchases" equation) of the baseline VAR equation on our proxy and we have computed the robust F statistic to check that a weak instrument problem is not present. Clearly, our econometric test confirms the validity of our proxy.

${ }^{16}$ By contrast, Andrade and Ferroni (2020) and Miranda-Agrippino and Ricco (forthcoming) emphasize that high-frequency monetary policy surprises are predictable using information available at the time of monetary policy decisions.

${ }^{17} 1 \%$ of the euro area GDP is roughly equivalent to a Eur 100 billion.
} 
positive region, indicating that the positive effects of the identified APP shock are particularly robust. Interestingly, the response of prices appear much more persistent, which is also a pattern observed in the effects of conventional monetary policy shocks.

The estimated Proxy-VAR suggests smaller price effects of APP shocks than those found in previous studies, including Garcia Pascual and Wieladek (2016) and Gambetti and Musso (2020). For example, Garcia Pascual and Wieladek (2016), using SVARs with a sign restrictions approach, find that the peak (core) prices effect is about 0.075 percentage points after an APP shock of $1 \%$ of GDP. While we employ industrial production as a proxy for output, the two previous studies use real GDP, making difficult the comparison of output effects.

Compared to the existing literature on U.S. and U.K. asset purchases, our proxy-SVAR suggests much lower effects. In the U.S., Weale and Wieladek (2016), Hesse, Hofmann, and Weber (2018), and Kim, Laubach, and Wei (2020) find an asset purchases shock equivalent to $1 \%$ of GDP leads to a rise in industrial production by about $0.58,0.20$ and 0.68 percentage points, respectively. For U.K., the peak output effect is about 0.20 and 0.25 percentage points according to Hesse, Hofmann, and Weber (2018) and Weale and Wieladek (2016), respectively. ${ }^{18}$ Thus, the effect is roughly 1.5 to 5 times smaller than in the U.S and the U.K. For consumer prices, our estimated model suggests also lower effects than U.S. and U.K estimates. For the U.S., Hesse, Hofmann, and Weber (2018), Weale and Wieladek (2016), and Kim, Laubach, and Wei (2020) estimate a maximum impact of an asset purchases shock equivalent to $1 \%$ of GDP on prices of about $0.20,0.62$, and 0.16 percentage points, respectively, while for the U.K., Hesse, Hofmann, and Weber (2018) and Weale and Wieladek (2016) document a rise of about 0.20 and 0.32 percentage points, respectively.

Turning to financial variables, the excess bond premium declines on impact roughly 2 basis points, and then remains below its pre-level shock for about one year. Recall that the excess bond premium is a component of corporate bond credit spreads that is not directly attributable to expected default risk. As argued by Gilchrist and Zakrajšsek (2012), it provides a measure of investors' sentiment and risk appetite in the corporate bond market. Its sizeable decrease signals a positive effect on corporates' financial conditions. Interestingly, the effect is far more persistent (lasting more than 1 year) than for the 10-year sovereign rates (see below), which means that APP has a persistent effect on private market conditions on top and not only related to the fall of risk free rates.

Our 10-year bond-OIS spread falls immediately about 1.5 basis points. This effect fades in about one month and is typically lower than other estimates using event study methodology. Andrade, Breckenfelder, De Fiore, Karadi, and Tristani (2016) compile a selection of event

\footnotetext{
${ }^{18} \mathrm{Kim}$, Laubach, and Wei (2020) report the effects of a "asset purchases" shock equivalent to $2.5 \%$ of nominal GDP. To make the comparison possible, we standardized it to a shock equivalent to 1\% of GDP.
} 
studies on the APP announcement which give an impact on the 10-year yield between -2.45 and -5.8 basis points (27-64 basis points for a 11\% GDP shock). The impact is typically lower on the 10-year rate than in the US or UK. Altavilla, Carboni, and Motto (forthcoming) among others attribute this difference to the financial conditions at the start of APP, noting financial stress was already low in January 2015, and "various yields and spreads [were] already compressed".

A back-of-the-envelope estimation suggests the January 2015 announcement (around 10\% of GDP) lowers the 10-year spread by around -15 basis points based on our results, which is not far from what Altavilla, Carboni, and Motto (forthcoming) find in their controlled event study on the January 2015 announcement: -17 basis points on a 1-day change in the 10-year Bund yield and -29 basis points in the euro area average 10-year yield. They also find that this immediate effect starts to fade from the day after, by looking at 2-day windows. By contrast, Eser, Lemke, Nyholm, Radde, and Vladu (2019) using a calibrated term-structure model with a supply factor find an impact of the January 2015 announcement on the 10year term premium (average of 4 biggest euro area countries) of about -50 basis points, with long-persisting effects.

These differences may come first by our data frequency. With monthly data, we capture a 10-year yields compression persistency, rather than relying uniquely on the day of announcement. Second, our 10-year spread controls for the evolution of the OIS curve, meaning that potential effects coming purely from a signalling channel is in principle taken out. This is an advantage of our measure as these signalling effects can be confounded with other instruments like the forward guidance strategy. By contrast, taking the 10-year bond-OIS spread is a model-free way to proxy the impact on the term premium which is in principle only related to APP.

VI.3. Variance Decomposition. Using variance decomposition, we now assess the relative importance of APP shocks in driving fluctuations in endogenous variables. Table 4 reports the percentage of the variances of the error made (at the median) in forecasting each endogenous variable due to APP shocks at forecasting horizons between the first (1M) and the fortyeighth months $(48 \mathrm{M})$ after the initial shock. The 68 percent error bands are indicated in brackets.

Variance decomposition shows that the contribution of disturbances to asset purchases to business cycle fluctuations is modest but non-negligible. These shocks explain about 12 (19) percent of long-run output (prices) variability. APP shocks account for about 19 percent of long-run fluctuations in the excess bond premium and for about 11 percent in the 10-year spread. The majority of their fluctuations are therefore caused by non-policy innovations, in 
line with the conventional wisdom that monetary policy contributes little to business cycle fluctuations. Note also that posterior uncertainty surrounding these estimates is large.

Interestingly, long-run variation in asset purchases is dominated by sources of variation other than policy. APP shocks explain less than half of its variation in the long-run. This implies most APP actions have historically been systematic reactions to the state of the economy.

VI.4. Historical Decomposition. This section looks at the cumulative role played by the estimated APP shocks in driving the variables of the model. Figure 8 shows the historical decomposition of variables with respect to the impact of the APP shock. In particular, we suppress APP shocks throughout the sample in order to quantify their importance. To do so, we simply set the disturbances to APP to zero. The actual data (solid line) and the median counterfactual paths (dotted line) with the $68 \%$ and $90 \%$ error bands in blue areas for each endogenous variable are displayed.

The estimated model shows modest but non-negligible responses of output and prices to APP shocks, and thus rules out from the start a strong explanatory role in macroeconomic movements by APP shocks. As can be seen from the figure, the contribution of APP shocks at the median is sometimes positive sometimes negative, but uncertainty about the estimates remains relatively large as shown by the $68 \%$ and $90 \%$ posterior probability bands, which makes the interpretation of the results difficult. Finally, the history of asset purchases is attributed almost entirely to nonpolicy sources since the counterfactual path follows closely its actual path throughout the sample, meaning that most of the observed variations in asset purchases is systematically responsive to the state of the economy.

VI.5. Robustness of the results. In order to assess the robustness of our results, we study a number of alternative specifications. First, we exclude January 2015 from the sample in Section VI.5.1. Second, Section VI.5.2 employs an alternative proxy, which is built only from market participants who expect changes in ECB's announcements. Third, our structural estimation is carried out by ordering the proxy first in a recursive VAR in Section VI.5.3. Fourth, instead of scaling the size of asset purchases with GDP, we use the volume of free float in Section VI.5.4. For brevity the results of this section are available in the Online Appendix.

VI.5.1. Excluding January 2015. In absolute terms, the largest APP shock occurred in January 2015, the date of the introduction of APP. Given the small sample size, this date might be the main driver of our results. To check whether our results depend on this date, we re-estimate our model on a sample that starts in February 2015. We obtain similar results, as shown in D.1. 
VI.5.2. Alternative proxy. In our baseline specification, our preferred measure of surprises used as a proxy takes into account the fact that a (small) proportion of respondents were not expected the announcement of a new APP recalibration. Their expectations were set to zero. In this section, we recompute the surprises using only the answers by the respondents who expected an APP recalibration at the next Governing Council. The resulting new time series proxy is depicted in Figure D.2 (thereafter called "reweighted proxy"), together with the baseline proxy. Qualitatively, the proxy delivers similar values than the baseline proxy. Quantitatively, there are however several major differences. The most striking difference between both proxies is found in the September 2019 recalibration. While the baseline proxy indicates unexpected changes in APP by about 5 percent of GDP, such a surprise is only about 3 percent of GDP for the reweighted proxy. Another difference with the baseline proxy is that there is no significant surprise in APP in June 2018. Finally, the small difference between both proxies in January 2015 reveals that the introduction of APP were almost fully expected by all market participants.

Given the sizeable differences between proxies, we re-estimate our SVAR model by replacing our baseline proxy by our reweighted proxy. Figure D.3 displays the impulse responses. Clearly, changing the construction of our proxy does not affect the dynamics effects of APP shocks. Impulse responses are close to those reported with the VAR identified from the baseline proxy; effects of APP shocks are still expansionary.

VI.5.3. Proxy within a recursive VAR. A number of studies employ an "internal instrument" strategy consisting in ordering the proxy first in a recursive (i.e., Cholesky) VAR instead of the "external instrument" approach. Notable examples include Kilian (2009), Ramey (2011), Miranda-Agrippino and Ricco (forthcoming), and Jarociński and Karadi (2020). Through the properties of the Cholesky decomposition, the identifying restrictions given by equations (4) and (5) still hold. According to Plagborg-Møller and Wolf (forthcoming), the "internal instrument" strategy leads to valid impulse response estimates even if the proxy is contaminated with measurement error that is unrelated to the shock of interest. Furthermore, it yields to estimates that are closely tied to those obtained from the "local projections" approach proposed by Jordà (2005) at short horizons (see Corollary 1 in Plagborg-Møller and Wolf (forthcoming)).

As a robustness check, we estimate our baseline SVAR model using the "internal instrument" strategy. We augment our VAR to include the proxy and order it first using a recursive ordering. By doing so, we are also able to check whether our results remain valid through a "local projections" approach. Impulse responses are displayed in Figure D.4. The responses are qualitatively similar to the responses of Figure 7 which are obtained from the "external 
instrument" approach. But there are notable quantitative differences. First, the response of industrial production is less precisely estimated, and there is a posterior probability mass that lies within a region of negative values when looking at $90 \%$ error bands. Second, the impact on the excess bond premium appears slightly stronger. At its peak, the decline is about one basis point lower.

VI.5.4. Free float. In this section, we explore an alternative scaling of our shock variable. In our baseline specification, we normalize the APP shocks by the euro area GDP. While this scaling is consistent with most of the literature, we may use instead the stock of debt really available in the market ("free float"), in the spirit of Altavilla, Carboni, and Motto (forthcoming) and Eser, Lemke, Nyholm, Radde, and Vladu (2019).

This approach is notably guided by the preferred habitat theory. Intuitively, the amount of debt held by inelastic investors (e.g. "preferred habitat" debt with particular characteristics in terms of maturity, invested in held-to-maturity portfolios) is in a way retrenched from the free float available for trading in the market. Vayanos and Vila (2009) develop formally a term-structure model in which the yield curve response to a bond supply shock vary depending on the residual debt to be held by non-preferred habitat investors.

We follow Eser, Lemke, Nyholm, Radde, and Vladu (2019) in defining the "free float" as the amount outstanding of market debt held by investors other than the ECB in its monetary policy portfolio and by insurance and pension funds (ICPF), know to be inelastic investors. ${ }^{19}$ To do so, we use the Securities Holdings statistics Database (SHS-S), which tracks quarterly the holdings of European investors at the security levels. Free float hovers around Eur 6,000 billion from 2013Q4 and 2015Q1 and then steadily decreases to Eur 4,500 billion, reflecting the APP purchases. The free float rises again after December 2018 and the end of net purchases. We rescale our APP surprises and the APP announced size in the SVAR on this free float measure (contemporaneous and lagged in 2014Q1 as for GDP), Impulse responses yield extremely similar results in both cases, and we do not report them for this reason. These results are available upon request.

\section{Historical Counterfactuals}

Our estimated model implies not only that APP shocks have accounted for little of the historical pattern of business cycles, but also that they account for a relatively important but non-overwhelming proportion of variation in asset purchases. This implies that most ECB actions have historically been systematic reactions to the state of the economy. Assessment of the effects of APP policy, as opposed to the effects of unpredictable changes in policy,

\footnotetext{
${ }^{19}$ Due to data limitation, we cannot include foreign officials in the inelastic holdings.
} 
must therefore consider what would have happen if the systematic component of APP were different. In this section, we now run a number of counterfactual exercises to assess the role of the systematic part of APP by considering what would have happened if major APP recalibrations would not have been implemented.

The procedure is straightforward. Given the actual data, a set of draws is generated from the posterior distribution using the algorithm developed by Arias, Rubio-Ramírez, and Waggoner (2018). For each draw, we recover the sequence of APP shocks in the model. We then simulate the history (i.e., a set of new series), but replace the actual APP shocks by shocks such that APP recalibrations would not have happened. As a result, the counterfactual simulations report what would have happened if the systematic part of APP policy would not have responded to the economy. In these exercises, all other equations of the system are held fixed, which implied that changes in dynamics of the private sector is potentially ignored since private agents may change their behavior under the new policy. Our counterfactual scenarios potentially ignore the Lucas critique. That being said, and according to Leeper and Zha (2003), a counterfactual exercise may imply "a change in policy that does not significantly shift agents' belief about policy regime and does not generate quantitatively important expectations-formation effects of the kind Lucas (1976) emphasizes". Therefore, the distribution of structural APP shocks required may not necessarily violate the Lucas critique.

In Section VII.1, we discuss simulations for the four major APP recalibrations (December 2015 and March 2016 together, December 2016, October 2017 and June 2018 together, and September 2019) ${ }^{20}$ in Figures 9 to 12. The main conclusion is that the estimated APP policy changes do make a drastic difference. In each of these figures, the solid lines represent the actual series, while the dotted lines represent the series under the modified policies, along with their $68 \%$ and $90 \%$ error bands in blue areas. In Section VII.2, for each counterfactual, we quantify how implausible our APP counterfactual scenarios are using the "modesty statistics" developed by Antolín-Díaz, Petrella, and Rubio-Ramírez (2020).

VII.1. Counterfactual scenarios. We run a simulation in which the APP extensions by Eur 360 billion in December 2015 and Eur 240 billion in March 2016 would not have been implemented. The results are shown in Figure 9. Here, we impose a sequence of APP shocks such that asset purchases remain at their pre-December 2015 level until November 2016, the last month before the date of the next major recalibration. We can see that (year-overyear) industrial production output growth would have reached a lower value by around one

\footnotetext{
${ }^{20}$ We study jointly December 2015 and March 2016 recalibrations due to their proximity. Also, given the relatively small amount announced in June 2018, we investigate its effects cumulated with the October 2017 recalibration. See Table 1 for the details about the amount announced by the ECB.
} 
percentage point at its peak, and the (year-over-year) HICP inflation level would have lowered at its maximum by 0.90 percentage points. This counterfactual simulation implies that the two first major APP recalibrations have mitigated the decline in output while preventing inflation to reach negative values.

When we repeat our exercise with December 2016 recalibration (Eur 540 billion), we obtain the results in Figure 10. This policy counterfactual, in which the path of asset purchases remains constant from December 2016 to September 2017, would have kept output lower by around 0.90 percentage points at its peak, and would have delivered a lower inflation by about the same amount. Clearly, this recalibration has been successful in preventing mounting deflationary pressures. Note, however, that the response of prices is less precisely estimated since there is a posterior probability mass that lies above the actual series in 2018. Furthermore, without the policy intervention taken by the ECB, the excess bond premium would have been a great deal higher, while the 10-year spread would been slightly higher but only during a very short period.

The effects of the absence of October 2017 (Eur 270 billion) and June 2018 (Eur 45 billion) recalibrations are shown in Figure 11. The major difference with the previous simulations is that the size of this APP extension has been relatively smaller but its duration were much longer. Indeed, we assume an intervention that maintains the level of asset purchases to its pre-October 2017 level until August 2019, the last month before the announcement date of the "open-ended" recalibration. Interestingly, our counterfactual simulation produces modest effects on output in the beginning of 2018, but then leaves the time path of output almost unchanged for the rest of the sample. By contrast, the simulation cuts inflation in the late 2017, and keeps it well below historical values (by about 0.4 percentage points) for most of 2018 and 2019. Also noticeable is the long-term deterioration of financial intermediaries' financial positions as shown through the excess bond premium.

The last simulation in which September 2019 recalibration (Eur 700 billion) would not have been put in place is reported in Figure 12. At its peak, inflation would have reached a lower value by around 0.25 percentage point, while effects on output remain relatively modest, though not negligible. As shown by both financial variables, financial conditions would have been tighter without the ECB intervention. Note however that, since our data sample ends in December 2019, we cannot fully evaluate the impact of this recalibration on the economy.

Overall, our counterfactual simulations provide strong evidence that the ECB APP recalibrations had beneficial effects both on the real and financial economy since 2015, and prevented several times inflation to fall into negative territory.

To compare our estimates with the literature, we record the estimated effects of the systematic part of asset purchases on output (i.e., real GDP or industrial production) and inflation 
(consumer prices) based on major studies' baseline model. Following the Fabo, Jančoková, Kempf, and Pástor (2020)'s rule, we record the effects on the level - the level of output and the price level. We denote $Y$ the actual level of the outcome variable (i.e., with asset purchases) and $\hat{Y}$ its counterfactual level (i.e., without asset purchases), and derive the percentage difference, $(Y-\hat{Y}) / Y$. We standardize the effects to a common asset purchases increase equal to $1 \%$ of the respective country's GDP around the time asset purchases was first implemented. We proceed in a similar manner with our estimates by taking the average of the median peak effects on the level of both variables among the first three APP recalibrations: December 2015 \& March 2016, December 2016, and October 2017 \& June 2018, and then standardize the effects in the same way as above. We do not include the last APP recalibration since we have not fully evaluated its impact. The (standardized) peak effects drawn from our baseline estimates are reported in the Online Appendix in Figures E.1 and E.2.

Table 5 shows the estimated effects of asset purchases on the levels of output and prices for our baseline and major studies' estimates. For prices, our peak effects are smaller than those from Andrade, Breckenfelder, De Fiore, Karadi, and Tristani (2016) and Weale and Wieladek (2016), but much larger than those from Garcia Pascual and Wieladek (2016), Gambetti and Musso (2020), and Baumeister and Benati (2013). For output, the estimate of the peak effect lies within the high side of the range of values reported by the literature.

VII.2. The plausibility of counterfactual scenarios. In this section, we examine whether our counterfactual simulations can be regarded as "modest policy interventions" in the sense of Leeper and Zha (2003). The idea is to assess the plausibility of the counterfactual paths for each endogenous variable of the VAR system from the perspective of a forecast. If the distribution of a conditional forecast under a policy intervention deviates significantly from the unconditional distribution, then the alternative policy should be deemed implausible; there is something that has changed in the SVAR system. As a consequence, conditional forecasts are not viewed as credible, and the formation of expectations need to be taken into account when forecasting under this alternative policy.

Using the methodology developed in Antolín-Díaz, Petrella, and Rubio-Ramírez (2020), we construct our conditional forecasts (or also called "structural scenarios") by choosing a sequence of APP shocks that keep asset purchases constant over a predefined horizon, which is specific to each round of interest. Other shocks of the model are perturbed stochastically but without any constraint. Conditional forecasts are done directly on the structural form of the VAR, as opposed to the reduced form as in Waggoner and Zha (1999), which does not require identifying the structural shocks. This allows us to guarantee that the path of 
variables results from a sequence of APP shocks that keep asset purchases constant over a predefined horizon.

We compute four conditional and unconditional forecasts over an horizon of $h=48$ months by taking as initial conditions the data up to the announcement date of each major recalibration. Our forecasts are based on the VAR estimated over the entire sample period from November 2014 to December 2019. The reason is simply that the sample period would be otherwise too short to produce reasonable estimates, which would lead to more dispersed posterior distributions. For brevity the conditional and unconditional forecasts are available in Figure F.1 in the Online Appendix.

Following Antolín-Díaz, Petrella, and Rubio-Ramírez (2020), we now quantify how plausible a structural scenario is by determining how "far" the distribution of conditional forecast is from the unconditional distribution using the Kullback-Leibler (KL) divergence as "modesty statistics". Equivalently, this amounts to determining how different the distribution of the structural shocks compatible with the structural scenario is from the unconditional distribution of the structural shocks (i.e., from the standard normal distribution). By doing so, we take into account the uncertainty induced by the future realization of all shocks in the model, as opposed to the original framework of Leeper and Zha (2003), in which only policy shocks are active. ${ }^{21}$ The KL divergence between the distribution of the structural shocks, $\mathcal{N}_{U}$, and the unconditional distribution of structural shocks, $\mathcal{N}_{S S}$, is given as follows

$$
D_{K L}\left(\mathcal{N}_{U}|| \mathcal{N}_{S S}\right)=\frac{1}{2}\left(\operatorname{tr}\left(\Sigma_{\varepsilon}^{-1}\right)+\mu_{\varepsilon}^{\prime} \Sigma_{\varepsilon}^{-1} \mu_{\varepsilon}-n h+\ln \left(\operatorname{det} \Sigma_{\varepsilon}\right)\right)
$$

where $\operatorname{tr}$ denotes the trace of a matrix, det denotes the determinant, and $\mu_{\varepsilon}$ and $\boldsymbol{\Sigma}_{\varepsilon}$ are the mean and variance of the shocks under the conditional forecasts.

In order to ease the interpretation of the KL divergence and to say how far the conditional forecast is from the unconditional forecast, we "calibrate" the KL divergence along the lines of McCulloch (1989); i.e., the discrimination information between the flips of a fair coin and a biased coin. $D_{K L}(\operatorname{Bern}(0.5) \| \operatorname{Bern}(q))$, is proposed to calibrate the KL divergence, where $\operatorname{Bern}(q)$ is a Bernoulli distribution with probability $q$. Given the dimensional issues with the Bernouilli distribution, we follow Antolín-Díaz, Petrella, and Rubio-Ramírez (2020) and replace it by a binomial distribution. It follows that

$$
q=\frac{1+\sqrt{1-\mathrm{e}^{-\frac{2 z}{n h}}}}{2}
$$

${ }^{21}$ Adolfson, Laséen, Lindé, and Villani (2005) and Benati (2021) have also taken into account the uncertainty induced by all shocks of the model to assess the plausibility of some conditional forecasts. However, they do not use the KL divergence as modesty statistics. 
where $z=D_{K L}\left(\mathcal{N}_{U}|| \mathcal{N}_{S S}\right)$. It can be shown that $q \in[0.5 ; 1]$. Thus, a value of $q$ close to 1 suggests that the distribution of the structural shocks under the structural scenario considered is very far from the unconditional distribution of the shocks, and therefore that such a policy intervention can be regarded as implausible or, say differently, not "modest" in the sense of Leeper and Zha (2003). By contrast, a value of $q$ close to 0.5 makes the intervention highly plausible.

Table 6 reports the median of "modesty statistics" for each counterfactual experiment using the KL divergence and its calibration as proposed above along with 68 probability intervals. The first striking result is that the calibrated $q$ is below 1 with narrow probability intervals for all four cases, meaning that our counterfactual experiments are all plausible. The least likely policy intervention among the ones considered is October 2017. Although the intervention is relatively small, the overall intervention is very persistent since the intervention is in place until August 2019. As a consequence, this requires a sequence of APP shocks that substantially deviate from their unconditional distribution. This result corroborates the Leeper and Zha (2003)'s evidence, namely that the longer the intervention last the least likely the policy is plausible. Say it differently, expectations-formation effects become apparent at longer horizons.

\section{CONCLUSION}

In this paper we assess the macroeconomic impact of the ECB's asset purchase programme and its recalibrations within a Proxy-SVAR framework. We propose a novel proxy for exogenous APP shocks by exploiting quantitative surveys that report market participants' expectations ahead of each key announcement dates. We derive surprises from the difference between these expectations and the ECB announcement. Our computed surprises, that we cross-check using four independent sources, prove to be in line with the financial press comments' on each major APP decision. Estimating the effect of APP shocks identified according to this methodology leads to the following conclusions and policy implications:

- APP shocks have expansionary effects: an immediate increase in asset purchases equivalent one percent of GDP leads to a maximum impact in industrial production and consumer prices by 0.15 percent and 0.06 percent, respectively. Even if the 10year impact is short-lived, the macroeconomic impact is sizeable and persistent. This implies high-frequency event studies focused on yields may not capture the complex macroeconomic effect of APP.

- The contribution of these shocks to business cycle fluctuations is modest but nonnegligible. They explain less than a fifth of the long-run variability in output and consumer prices. 
- Counterfactual estimates imply the APP and its successive recalibrations were central in stimulating the economy, and notably in preventing inflation to fall into negative territory in 2015 and 2016.

Our analysis leaves several interesting avenues for future research. For instance, it would be interesting to investigate the potentially nonlinear effects of asset purchases on aggregate activity. Indeed, from a theoretical perspective, Cúrdia and Woodford (2011) claim, under an active credit policy by central banks, that "it is only at times of unusual financial distress that [this] will have substantial benefits." Another possible direction is to estimate a ProxySVAR of the kind we have developed based on data from other countries that implemented asset purchases. 


\section{REFERENCES}

Adolfson, M., S. Laséen, J. Lindé, and M. Villani (2005): "Are Constant Interest Rate Forecasts Modest Policy Interventions? Evidence from a Dynamic Open-Economy Model," International Finance, 8(3), 509-544.

Altavilla, C., L. Brugnolini, R. S. Gürkaynak, R. Motto, and G. Ragusa (2019): "Measuring euro area monetary policy," Journal of Monetary Economics, 108(C), $162-179$.

Altavilla, C., G. Carboni, and R. Motto (forthcoming): "Asset purchase programmes and financial markets: lessons from the euro area," International Journal of Central Banking.

Altavilla, C., D. Giannone, and M. Lenza (2016): "The Financial and Macroeconomic Effects of the OMT Announcements," International Journal of Central Banking, 12(3), 2957.

Andrade, P., J. Breckenfelder, F. De Fiore, P. Karadi, and O. Tristani (2016):

"The ECB's Asset Purchase Programme: an Early Assessment," Working Paper Series 1956, European Central Bank.

Andrade, P., And F. Ferroni (2020): "Delphic and odyssean monetary policy shocks: Evidence from the euro area," Journal of Monetary Economics.

Antolín-Díaz, J., I. Petrella, and J. Rubio-Ramírez (2020): "Structural Scenario Analysis with SVARs," Journal of Monetary Economics.

Arias, J. E., J. F. Rubio-Ramírez, and D. F. Waggoner (2018): "Inference in Bayesian Proxy-SVARs," Working Papers 18-25, Federal Reserve Bank of Philadelphia.

BAI, J., AND S. NG (2002): "Determining the Number of Factors in Approximate Factor Models," Econometrica, 70(1), 191-221.

Baumeister, C., and L. Benati (2013): "Unconventional Monetary Policy and the Great Recession: Estimating the Macroeconomic Effects of a Spread Compression at the Zero Lower Bound," International Journal of Central Banking, 9(2), 165-212.

Benati, L. (2021): "Leaning Against House Prices: A Structural VAR Investigation," Journal of Monetary Economics.

Boeckx, J., M. Dossche, A. Galesi, B. Hofmann, and G. Peersman (2019): "Do SVARs with sign restrictions not identify unconventional monetary policy shocks?," BIS Working Papers 788, Bank for International Settlements.

Boeckx, J., M. Dossche, and G. Peersman (2017): "Effectiveness and Transmission of the ECB's Balance Sheet Policies," International Journal of Central Banking, 13(1), $297-333$. 
Caldara, D., and E. Herbst (2019): "Monetary Policy, Real Activity, and Credit Spreads: Evidence from Bayesian Proxy SVARs," American Economic Journal: Macroeconomics, 11(1), 157-192.

CaO, G., And A. Foerster (2013): "Expectations of large-scale asset purchases," Economic Review, (Q II), 5-29.

Chen, H., V. Cúrdia, and A. Ferrero (2012): "The Macroeconomic Effects of Largescale Asset Purchase Programmes," Economic Journal, 122(564), 289-315.

Chung, H., J.-P. Laforte, D. L. Reifschneider, and J. C. Williams (2011): "Estimating the macroeconomic effects of the Fed's asset purchases," FRBSF Economic Letter, (jan31).

Coeuré, B. (2017): "Bond scarcity and the ECB's asset purchase programme," Speech by Benoît Couré, Member of the Executive Board of the ECB, at the Club de Gestion Financière d'Associés en Finance, Paris, 3 April $201 \%$.

Cúrdia, V., And M. Woodford (2011): "The Central-Bank Balance Sheet as an Instrument of Monetary Policy," Journal of Monetary Economics, 58(1), 54-79.

De SAntis, R. A. (2018a): "Unobservable country bond premia and fragmentation," Journal of International Money and Finance, 82(C), 1-25.

- (2018b): "Unobservable systematic risk, economic activity and stock market," Journal of Banking \& Finance, 97(C), 51-69.

DrautzBurg, T. (forthcoming): "A Narrative Approach to a Fiscal DSGE Model," Quantitative Economics.

Elbourne, A., And K. Ji (2019): "Do zero and sign restricted SVARs identify unconventional monetary policy shocks in the euro area?," CPB Discussion Paper 391, CPB Netherlands Bureau for Economic Policy Analysis.

Eser, F., W. Lemke, K. Nyholm, S. Radde, and A. L. Vladu (2019): "Tracing the impact of the ECB's asset purchase programme on the yield curve," Working Paper Series 2293, European Central Bank.

Fabo, B., M. JanC̆oková, E. Kempf, and L. PÁstor (2020): "Fifty Shades of QE: Conflicts of Interest in Economic Research," NBER Working Papers 27849, National Bureau of Economic Research, Inc.

Favara, G., S. Gilchrist, K. F. Lewis, And E. ZakrajŠEk (2016): "Recession Risk and the Excess Bond Premium," FEDS Notes 2016-04-08, Board of Governors of the Federal Reserve System (U.S.).

Forni, M., And L. Gambetti (2014): "Sufficient information in structural VARs," Journal of Monetary Economics, 66(C), 124-136. 
Gambacorta, L., B. Hofmann, and G. Peersman (2014): "The Effectiveness of Unconventional Monetary Policy at the Zero Lower Bound: A Cross-Country Analysis," Journal of Money, Credit and Banking, 46(4), 615-642.

Gambetti, L., And A. Musso (2020): "The macroeconomic impact of the ECB's expanded asset purchase programme (APP)," European Economic Review, 130.

Garcia Pascual, A., and T. Wieladek (2016): "The European Central Bank's QE: A new hope," CEPR Discussion Papers 11309, C.E.P.R. Discussion Papers.

Gertler, M., And P. Karadi (2015): "Monetary Policy Surprises, Credit Costs, and Economic Activity," American Economic Journal: Macroeconomics, 7(1), 44-76.

Gilchrist, S., ANd E. ZAKRAJS̆EK (2012): "Credit Spreads and Business Cycle Fluctuations," American Economic Review, 102(4), 1692-1720.

Gürkaynak, R. S., B. Sack, and E. Swanson (2005): "Do Actions Speak Louder Than Words? The Response of Asset Prices to Monetary Policy Actions and Statements," International Journal of Central Banking, 1(1).

Hammermann, F., K. Leonard, S. Nardelli, and J. von Landesberger (2019): "Taking stock of the Eurosystem's asset purchase programme after the end of net asset purchases," Economic Bulletin Articles, 2.

Hartmann, P., and F. Smets (2018): "The first twenty years of the European Central Bank: monetary policy," Working Paper Series 2219, European Central Bank.

Hesse, H., B. Hofmann, and J. M. Weber (2018): "The macroeconomic effects of asset purchases revisited," Journal of Macroeconomics, 58(C), 115-138.

Jarociński, M., And P. Karadi (2020): "Deconstructing Monetary Policy Surprises-The Role of Information Shocks," American Economic Journal: Macroeconomics, 12(2), 1-43. JordÀ, O. (2005): "Estimation and Inference of Impulse Responses by Local Projections," American Economic Review, 95(1), 161-182.

Kilian, L. (2009): "Not All Oil Price Shocks Are Alike: Disentangling Demand and Supply Shocks in the Crude Oil Market," American Economic Review, 99(3), 1053-69.

Kim, K., T. Laubach, and M. Wei (2020): "Macroeconomic Effects of Large-Scale Asset Purchases: New Evidence," Finance and Economics Discussion Series 2020-047, Board of Governors of the Federal Reserve System (U.S.).

Leeper, E. M., C. A. Sims, and T. Zha (1996): "What Does Monetary Policy Do?," Brookings Papers on Economic Activity, 27(2), 1-78.

LeEper, E. M., And T. Zha (2003): "Modest policy interventions," Journal of Monetary Economics, 50(8), 1673-1700.

Lenza, M., And G. E. Primiceri (2020): "How to Estimate a VAR after March 2020," CEPR Discussion Papers 15245, C.E.P.R. Discussion Papers. 
Lhuissier, S. (2017): “Financial Intermediaries' Instability and Euro Area Macroeconomic Dynamics," European Economic Review, 98(C), 49-72.

Lhuissier, S., And U. Szczerbowicz (2018): "Monetary Policy and Corporate Debt Structure," Discussion paper.

Li, W., and F. Zanetti (2016): "The Effect of Monetary Policy Shocks in the United Kingdom: an External Instruments Approach," Working Paper.

Liu, P., K. Theodoridis, H. Mumtaz, and F. Zanetti (2019): "Changing Macroeconomic Dynamics at the Zero Lower Bound," Journal of Business 85 Economic Statistics, $37(3), 391-404$.

LucAs, R. J. (1976): "Econometric policy evaluation: A critique," Carnegie-Rochester Conference Series on Public Policy, 1(1), 19-46.

McCulloch, R. E. (1989): "Local Model Influence," Journal of the American Statistical Association, 84(406), 473-478.

Mertens, K., and M. O. Ravn (2013): "The Dynamic Effects of Personal and Corporate Income Tax Changes in the United States," American Economic Review, 103(4), 1212-47.

Miranda-Agrippino, S., And G. Ricco (forthcoming): "The Transmission of Monetary Policy Shocks," American Economic Journal: Macroeconomics.

Peersman, G., and F. Smets (2003): "The monetary transmission mechanism in the euro area: more evidence from VAR analysis," in A Study by the Eurosystem Monetary Transmission Network, ed. by I. Angeloni, A. K. Kashyap, and B. Mojon, pp. 36-55. Cambridge University Press.

Pfister, C., And J.-G. Sahuc (2020): "Unconventional Monetary Policies: A StockTaking Exercise," Discussion paper.

Plagborg-Møller, M., and C. K. Wolf (forthcoming): "Local Projections and VARs Estimate the Same Impulse Responses," Econometrica.

Ramey, V. A. (2011): "Identifying Government Spending Shocks: It's all in the Timing," The Quarterly Journal of Economics, 126(1), 1-50.

Rossi, B. (2020): "Identifying and estimating the effects of unconventional monetary policy: How to do it and what have we learned?," The Econometrics Journal.

Rostagno, M., C. Altavilla, G. Carboni, W. Lemke, R. Motto, A. Saint GuilHEM, AND J. YiAngou (2019): "A tale of two decades: the ECB's monetary policy at 20," Working Paper Series 2346, European Central Bank.

Rubio-Ramírez, J. F., D. F. Waggoner, and T. Zha (2010): "Structural Vector Autoregressions: Theory of Identification and Algorithms for Inference," Review of Economic Studies, 77(2), 665-696.

Sims, C. A. (1980): "Macroeconomics and Reality," Econometrica, 48(1), 1-48. 
Stock, J. H., And M. WAtson (2012): "Disentangling the Channels of the 2007-2009 Recession," Brookings Papers on Economic Activity, 44(1), 81-156.

Swanson, E. T. (2020): "Measuring the Effects of Federal Reserve Forward Guidance and Asset Purchases on Financial Markets," Journal of Monetary Economics.

Uhlig, H. (2005): "What Are the Effects of Monetary Policy on Output? Results from An Agnostic Identification Procedure," Journal of Monetary Economics, 52(2), 381-419.

Vayanos, D., And J.-L. Vila (2009): “A Preferred-Habitat Model of the Term Structure of Interest Rates," Fmg discussion papers, Financial Markets Group.

Waggoner, D. F., And T. Zha (1999): "Conditional Forecasts In Dynamic Multivariate Models," The Review of Economics and Statistics, 81(4), 639-651.

Weale, M., AND T. WieladeK (2016): "What are the macroeconomic effects of asset purchases?," Journal of Monetary Economics, 79(C), 81-93.

Wright, J. H. (2019): "Comment on "Measuring euro area monetary policy" by Carlo Altavilla, Luca Brugnolini, Refet Gürkaynak, Giuseppe Ragusa and Roberto Motto," Journal of Monetary Economics, 108, 180 - 184. 
Appendix A. TABLES

TABLE 1. ECB APP announcements 2015M1 - 2019M12

\begin{tabular}{llllrrrr}
\hline \hline Event & Date & Start & End & $\begin{array}{r}\text { Length } \\
\text { (month) }\end{array}$ & $\begin{array}{r}\text { Add. Pace } \\
(/ \text { month })\end{array}$ & $\begin{array}{r}\text { Add. amount } \\
\text { (bn Eur) }\end{array}$ & $\begin{array}{r}\text { Cumulated } \\
\text { (bn Eur })\end{array}$ \\
\hline Announcement & $22 / 01 / 2015$ & Mar-15 & Sep-16 & 19 & 60 & 1140 & 1140 \\
Extension & $03 / 12 / 2015$ & Sep-16 & Mar-17 & 6 & 60 & 360 & 1500 \\
Extension & $10 / 03 / 2016$ & Apr-16 & Mar-17 & 12 & 20 & 240 & 1740 \\
Extension & $08 / 12 / 2016$ & Apr-17 & Dec-17 & 9 & 60 & 540 & 2280 \\
Extension & $26 / 10 / 2017$ & Dec-17 & Sep-18 & 9 & 30 & 270 & 2550 \\
Extension & $14 / 06 / 2018$ & Sep-18 & Dec-18 & 3 & 15 & 45 & 2595 \\
Re-start & $12 / 09 / 2019$ & Nov-19 & open-ended & - & 20 & $700^{*}$ & 3315 \\
\hline
\end{tabular}

Source: ECB, Bloomberg. *The September 2019 restart is announced in an "open-ended" way, i.e., the ECB commits only to a monthly size, and gives two indications: net purchases will stop "shortly before" the next interest rate hike. We infer the total size from these parameters, their qualitative interpretation by market participants from surveys and quantitatively from the OIS curve. See section V for the detailed explanation. 
TABLE 2. Market expectations on APP announcement/re-calibration

\begin{tabular}{|c|c|}
\hline Dates & ource and comments \\
\hline $22-\mathrm{Ja}$ & $\begin{array}{l}\text { We use of a Bloomberg poll conducted on 19-Jan-2015. At the question "Do you expect the } \\
E C B \text { to announce QE at its Jan. 22 meeting ?", } 93 \% \text { of respondents answered "Yes", } 7 \% \\
\text { 'No" (over } 60 \text { respondents). The median estimate for the total size of purchases was } 550 \\
\text { billion Eur. }\end{array}$ \\
\hline 03-Dec-2015 & $\begin{array}{l}\text { We use a Bloomberg poll conducted on } 30-\mathrm{Nov}-2015.100 \% \text { of respondents (over } 53 \text { ) expected } \\
\text { an announcement at the Dec- } 2015 \text { GovC of an extension of APP. Information is sparse on } \\
\text { the expected additional amount. At the question "what will the ECB do?", } 79 \% \text { answered } \\
\text { "extend QE program past Sept. } 2016 \text { " and } 66 \% \text { "Increase purchases above EU60b/month". } \\
\text { Separate pools (notably one cited by Reuters on 04-Dec- } 2015 \text {, 'ECB day: market tumbles as } \\
\text { Draghi disappoint investors') indicate expectations of a } 6 \text { to } 12 \text { months extension at a } 70-75 \\
\text { billion Eur/month pace. We take the average and set the additional amount of purchases } \\
\text { at } 652.5 \text { billion Eur ( } 9 \text { months at } 72.5 \text { billion Eur) }\end{array}$ \\
\hline 10-Mar-2016 & $\begin{array}{l}\text { We use a Bloomberg poll conducted on 07-Mar-2016. At the question "what new measures } \\
\text { will Draghi announce on March 10?", } 73 \% \text { of respondents (over 59) answered "Expand QE } \\
\text { purchases above EUR60b/month" with a median increase by Eur } 15 \text { bn a month. The large } \\
\text { majority ( } 72 \% \text { ) expected an unchanged end in March } 2017 \text {. The Reuters poll gives the } \\
\text { median expected ("What monthly total do you expect the ECB to announce") at } 70 \text { billion } \\
\text { Eur/month. Therefore the median additional purchases were at Eur } 120 \text { billion ( }+10^{*} 12 \\
\text { months). }\end{array}$ \\
\hline 08-Dec- & $\begin{array}{l}\text { We use the additional questions asked in a Reuters poll "European Central Bank Monetary } \\
\text { Policy Poll - December 8, 2016", as the Bloomberg poll is less explicit about the next } \\
\text { GovC expectations. } 87 \% \text { ( } 52 \text { of } 60 \text { respondents) said 'the ECB will announce on Dec. } 8 \\
\text { an extension to its QE programme beyond the current plan of March 2017". The median } \\
\text { estimate was an extension from Mar- } 2017 \text { to Sep- } 2017 \text { at a monthly pace of } 80 \text { billion } \\
\text { Eur/month, or an additional amount of purchases of } 480 \text { billion Eur. }\end{array}$ \\
\hline 26-Oct-2017 & $\begin{array}{l}\text { We use a Bloomberg poll conducted on 18-Oct-2017. } 98 \% \text { of the } 57 \text { respondents expected a } \\
\text { decision at the } 26 \text {-Oct meeting regarding APP. The median estimate of additional purchases } \\
\text { was } 300 \text { billion Eur. }\end{array}$ \\
\hline 14-Jun-2018 & $\begin{array}{l}\text { We use a Bloomberg poll conducted on 7-Jun-2018. At the question "When Will ECB } \\
\text { Announce QE End Date?", } 30 \% \text { of respondents (over 56) answered "June } 2018 \text { ". The } \\
\text { median estimates of additional purchases to be announced after Sep- } 2018 \text { was } 45 \text { billion } \\
\text { Eur. }\end{array}$ \\
\hline 12-Sep-2019 & $\begin{array}{l}\text { We use a Bloomberg poll conducted on } 6 \text {-Sep- } 2019.59 \% \text { of respondents expected a decision } \\
\text { regarding the restart of APP at the Sep. } 12 \text { meeting. The median estimate of additional } \\
\text { purchases was } 12 \text { months at a pace of } 32.5 \text { billion Eur, or a cumulative additional amount } \\
\text { of } 390 \text { billion Eur. }\end{array}$ \\
\hline
\end{tabular}


TABLE 3. Selected newspapers' accounts on APP announcement/re-calibrations

\begin{tabular}{|c|c|}
\hline Dates & ource and comments \\
\hline 22 & $\begin{array}{l}\text { FT: "Mario Draghi's bond-buying plan outstrips expectations" https://www.ft.com/ } \\
\text { content/8f215db8-a256-11e4-9630-00144feab7de }\end{array}$ \\
\hline & $\begin{array}{l}\text { FT: "the measures seem to have disappointed market participants who were ex- } \\
\text { pecting even bolder steps" http://blogs.ft.com/the-world/liveblogs/2015-12- } \\
\text { 03/. The Guardian: "European stocks slide after ECB dashes hopes of major } \\
\text { QE expansion" https://www.theguardian.com/business/2015/dec/03/ecb-launches- } \\
\text { new-stimulus-package-eurozone }\end{array}$ \\
\hline $10-1$ & $\begin{array}{l}\text { FT: "The European Central Bank has unleashed a bigger than expected package of measures } \\
\text { to stimulate the eurozone economy, [...] The ECB raised the amount of bonds the eurozone's } \\
\text { central bankers buy each month under QE from Eur } 60 \mathrm{bn} \text { to Eur } 80 \mathrm{bn}-\text { a greater sum } \\
\text { than many analysts had expected." https://www.ft.com/content/9a45a960-e6ac-11e5- } \\
\text { a09b-1f8b0d268c39 }\end{array}$ \\
\hline 08 & $\begin{array}{l}\text { WSJ: "ECB Extends but Scales Back Stimulus, Whipsawing Markets" https: } \\
\text { //www.wsj.com/articles/ecb-to-extends-stimulus-program-by-nine-months- } \\
\text { at-reduced-rate-1481201978 }\end{array}$ \\
\hline $26-$ & $\begin{array}{l}\text { FT: "Although purchases under its historic quantitative easing programme will from January } \\
\text { be cut from the current pace of Eur } 60 \mathrm{bn} \text { a month to Eur } 30 \mathrm{bn} \text {, the scale of the reduction } \\
\text { matched the consensus among investors, economists and traders." https://www.ft.com/ } \\
\text { content/2849d4ec-ba24-11e7-9bfb-4a9c83ffa852 }\end{array}$ \\
\hline $14-\mathrm{Ju}$ & $\begin{array}{l}\text { FT: "ECB to phase out Eur } 2.4 \text { tn bond-buying programme by year end Euro falls as mar- } \\
\text { kets respond to cautious elements in plan to end QE" https://www.ft.com/content/ } \\
7514 \mathrm{a} 734-6 \mathrm{fbe}-11 \mathrm{e} 8-92 \mathrm{~d} 3-6 \mathrm{c} 13 \mathrm{e} 5 \mathrm{c} 92914\end{array}$ \\
\hline $12-\mathrm{Se}_{1}$ & $\begin{array}{l}\text { NYT: "The European Central Bank took unexpectedly aggressive steps on Thursday [...] } \\
\text { The measures }[\ldots] \text { go beyond what many analysts were expecting. Recent comments by } \\
\text { members of the Governing Council had cast doubt on whether the bank would restart } \\
\text { purchases of government and corporate bonds." https://www.nytimes.com/2019/09/12/ } \\
\text { business/ecb-europe-recession-stimulus.html }\end{array}$ \\
\hline
\end{tabular}


TABLE 4. Forecast Error Variance Decomposition

\begin{tabular}{cccccc}
\hline \hline Horizon & IP & Prices & EBP & Spread & APP \\
\hline \multirow{2}{*}{$1 \mathrm{M}$} & 5.88 & 9.02 & 16.89 & 9.44 & 91.19 \\
& {$[2.69 ; 11.81]$} & {$[2.71 ; 18.69]$} & {$[7.37 ; 29.21]$} & {$[3.39 ; 19.01]$} & {$[85.16 ; 95.21]$} \\
$6 \mathrm{M}$ & 8.46 & 14.14 & 21.21 & 9.24 & 77.02 \\
& {$[2.83 ; 19.90]$} & {$[4.07 ; 29.35]$} & {$[9.75 ; 35.29]$} & {$[4.51 ; 16.27]$} & {$[65.33 ; 86.03]$} \\
$12 \mathrm{M}$ & 11.32 & 16.29 & 20.85 & 10.33 & 63.63 \\
& {$[3.39 ; 25.59]$} & {$[4.41 ; 34.74]$} & {$[9.54 ; 34.04]$} & {$[5.42 ; 17.53]$} & {$[46.33 ; 76.60]$} \\
$24 \mathrm{M}$ & 12.24 & 18.53 & 19.59 & 11.03 & 49.22 \\
& {$[3.50 ; 27.55]$} & {$[4.61 ; 40.38]$} & {$[8.76 ; 33.50]$} & {$[5.84 ; 18.57]$} & {$[30.02 ; 66.88]$} \\
$36 \mathrm{M}$ & 12.22 & 19.53 & 19.33 & 11.46 & 44.73 \\
& {$[3.83 ; 27.94]$} & {$[4.68 ; 41.87]$} & {$[8.69 ; 33.49]$} & {$[6.25 ; 18.91]$} & {$[24.04 ; 63.40]$} \\
$48 \mathrm{M}$ & 12.74 & 19.61 & 19.35 & 11.64 & 42.47 \\
& {$[3.96 ; 28.24]$} & {$[4.97 ; 42.18]$} & {$[8.56 ; 33.43]$} & {$[6.38 ; 19.50]$} & {$[21.97 ; 61.92]$} \\
\hline
\end{tabular}

Note: Fraction of variances (computed from the posterior median) of each endogenous variables explained by APP shocks at various horizons. The 68 percent probability intervals are indicated in brackets.

TABLE 5. Standardized peak effects on prices and output

\begin{tabular}{lcccc}
\hline \hline & Country & Model & Prices (\%) & Output (\%) \\
\hline Baseline estimates & E.A & SVAR & 0.21 & 0.31 \\
& & & & \\
\hline Andrade, Breckenfelder, De Fiore, & E.A & DSGE & 0.41 & 0.12 \\
Karadi, and Tristani (2016) & & & & \\
Garcia Pascual and Wieladek (2016) & E.A & SVAR & 0.09 & 0.13 \\
Gambetti and Musso (2020) & E.A & SVAR & 0.04 & 0.02 \\
Baumeister and Benati (2013) & U.K & SVAR & 0.06 & 0.08 \\
Baumeister and Benati (2013) & U.S & SVAR & 0.06 & 0.09 \\
Weale and Wieladek (2016) & U.K & SVAR & 0.46 & 0.30 \\
Weale and Wieladek (2016) & U.S & SVAR & 0.96 & 0.96 \\
Chen, Cúrdia, and Ferrero (2012) & U.S & DSGE & 0.02 & 0.02 \\
Kim, Laubach, and Wei (2020) & U.S & SVAR & 0.19 & 0.93 \\
\hline
\end{tabular}

Note: This table summarizes the standardized peak effects on prices and output in the literature. The effects are standardized to a common increase size equal to $1 \%$ of the respective country's GDP around the time asset purchases was first introduced. 
TABLE 6. Plausibility of Counterfactual Scenarios

\begin{tabular}{|c|c|c|}
\hline & KL divergence & Calibrated q \\
\hline \multirow[t]{2}{*}{ Dec 2015 \& Mar 2016} & 31.87 & 0.72 \\
\hline & {$[29.57 ; \quad 35.30]$} & {$[0.72 ; 0.73]$} \\
\hline \multirow[t]{2}{*}{ Dec 2016} & 24.54 & 0.70 \\
\hline & {$[23.45 ; 25.64]$} & {$[0.69 ; \quad 0.70]$} \\
\hline \multirow[t]{2}{*}{ Oct 2017 \& Jun 2018} & 55.24 & 0.78 \\
\hline & {$[52.96 ; \quad 57.61]$} & {$[0.78 ; \quad 0.79]$} \\
\hline \multirow[t]{2}{*}{ Sep 2019} & 10.28 & 0.63 \\
\hline & {$[9.53 ; 11.56]$} & {$[0.63 ; 0.64]$} \\
\hline
\end{tabular}

Note: Median of the KL divergence and the calibrated q. The 68 percent probability intervals are indicated in brackets. 


\section{Appendix B. Figures}

FiguRE 1. Size and composition of the Eurosystem's balance sheet

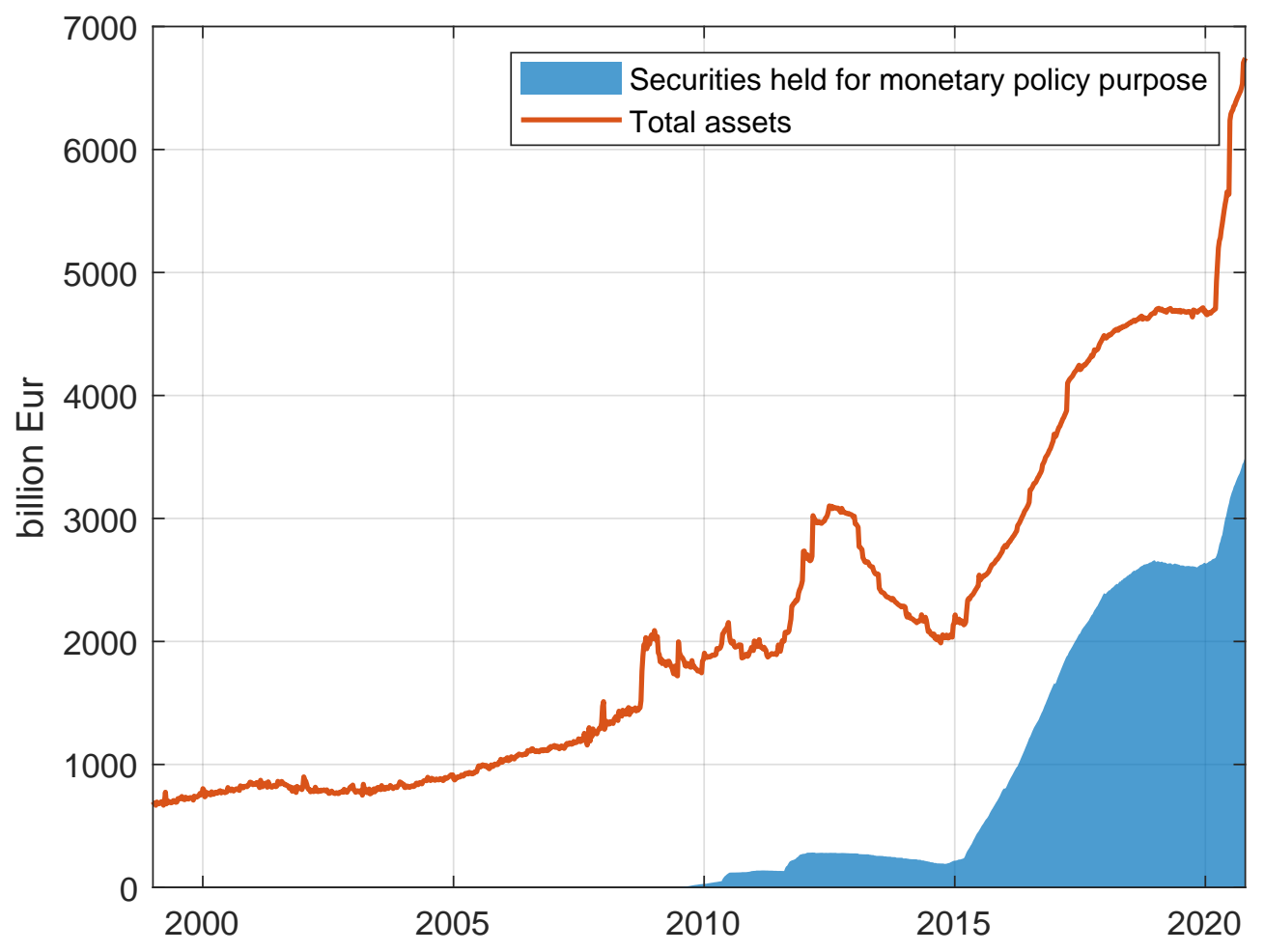

Note: Sample period: Jan 1999 - Oct 2020. Source: ECB Statistical Data Warehouse. 
Figure 2. Total APP size, as announced by the ECB

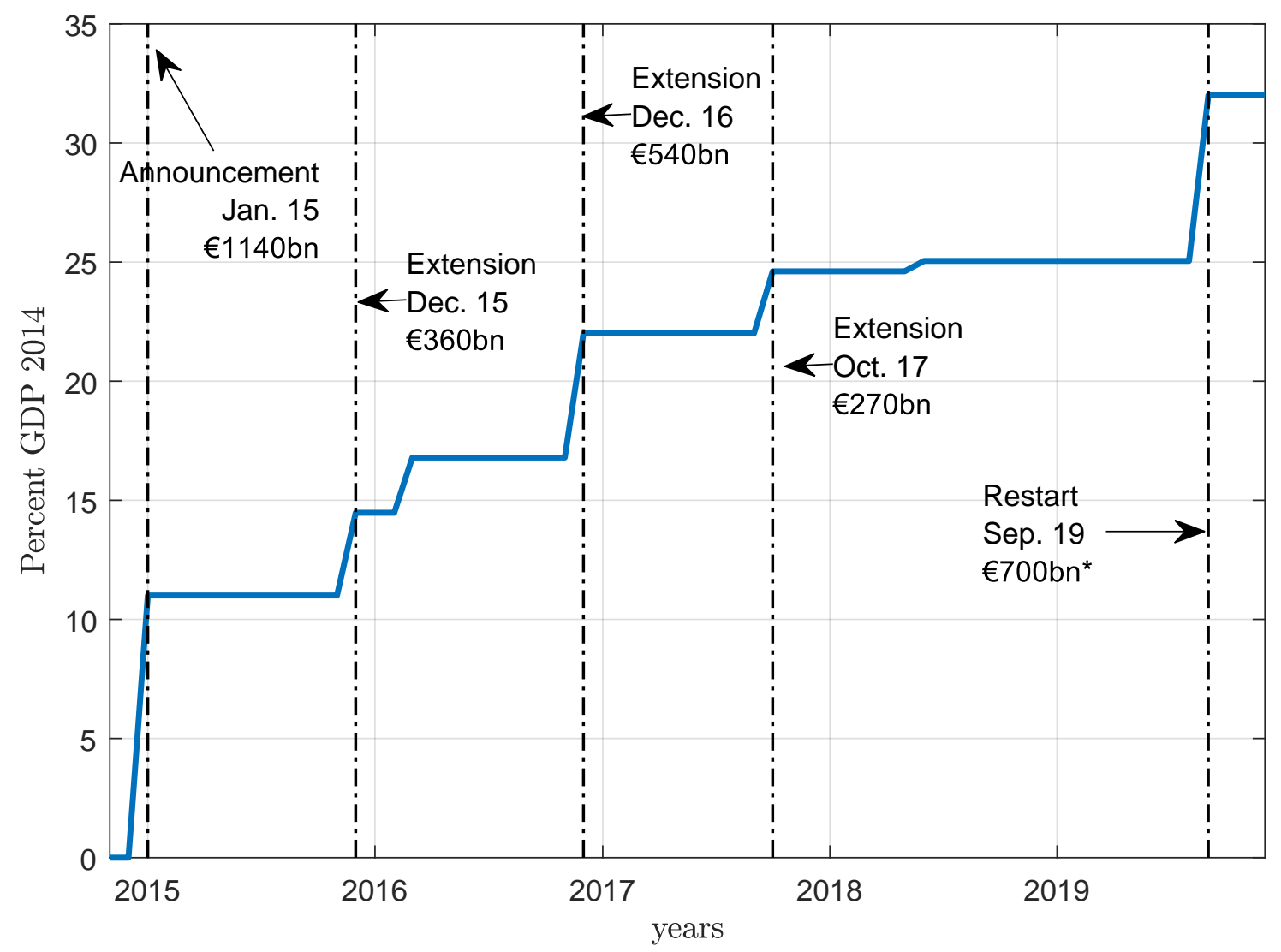

Note: Sample period: 2014.M11 - 2019.M12. * The Sept 2019 restart is announced in an "open-ended" way ie. ECB commits only to a monthly size, and gives two indications: net purchases will stop "shortly before" the next interet rate hike. We infer the total size from these parameters, their qualitative interpretation by market participants from surveys and quantitatively from the OIS curve. See section V for the detailed explanation.

Source: ECB, ECB Statistical Data Warehouse. 
FiguRE 3. Distribution of market expectations on APP recalibrations

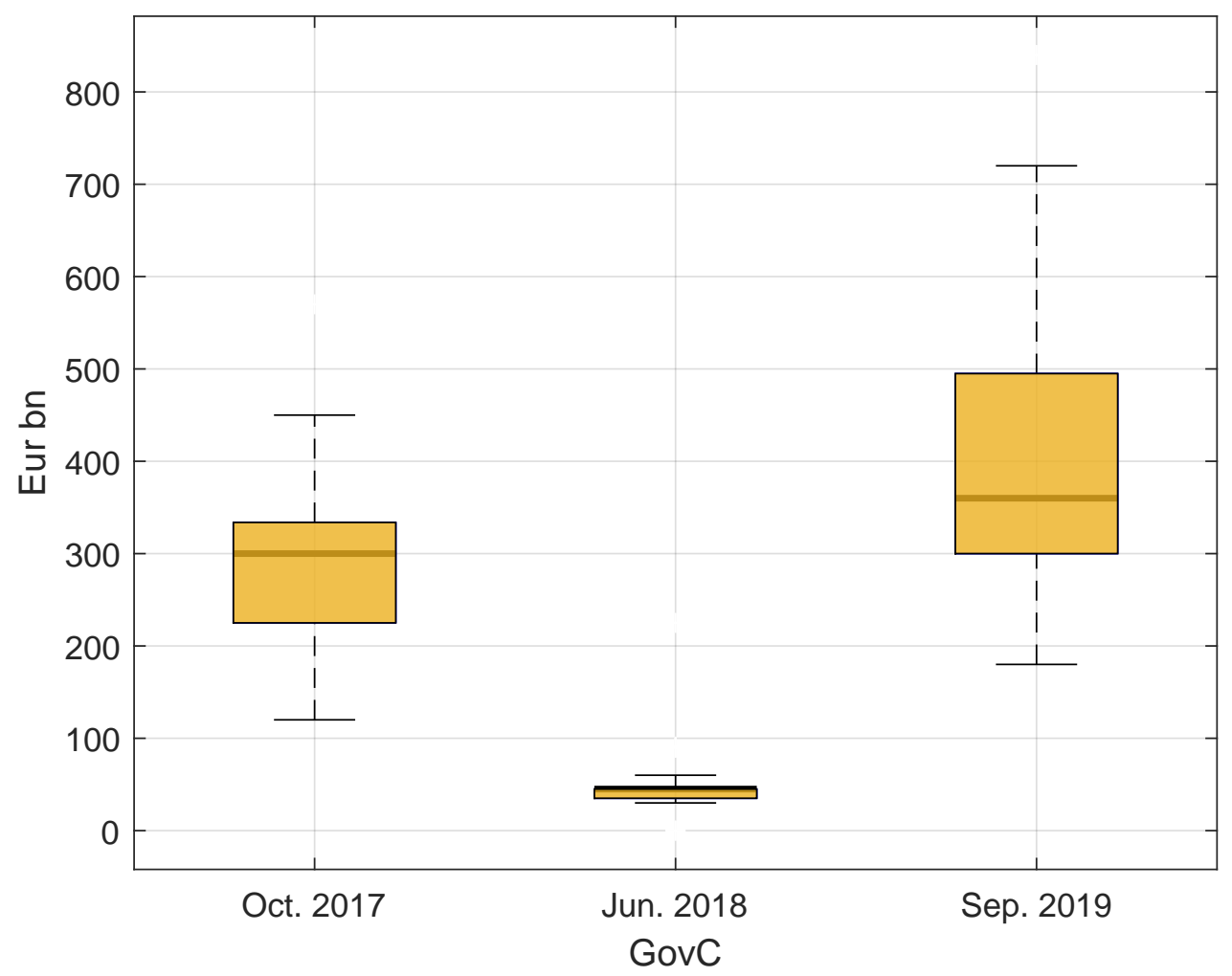

Note: This figure illustrates the distribution of market expectations on the additional APP purchases ahead of three key Governing Councils (GovC). Sources used are described in Table 2 , the respondents' distribution come from Bloomberg polls. We take the median value to compute our surprise measure. Boxes represent the 25/75 percentiles and bars min/max once outliers are removed. 
Figure 4. Proxy.

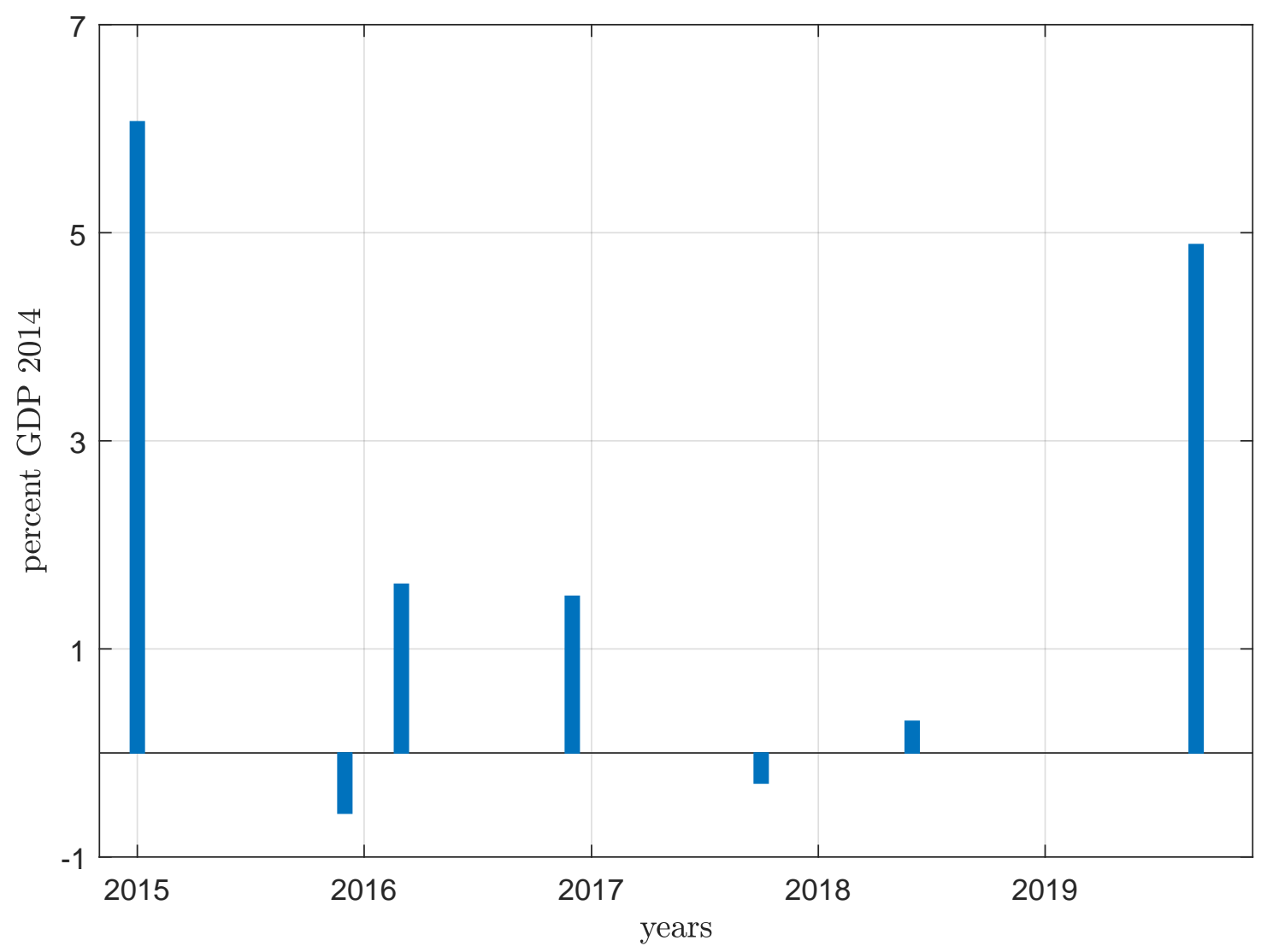

Note: Sample period: 2014.M11 — 2019.M12. Unexpected Components around Governing Council Announcements. Unexpected Components are scaled to GDP 2014. 
Figure 5. Historical Path of Structural APP Shocks

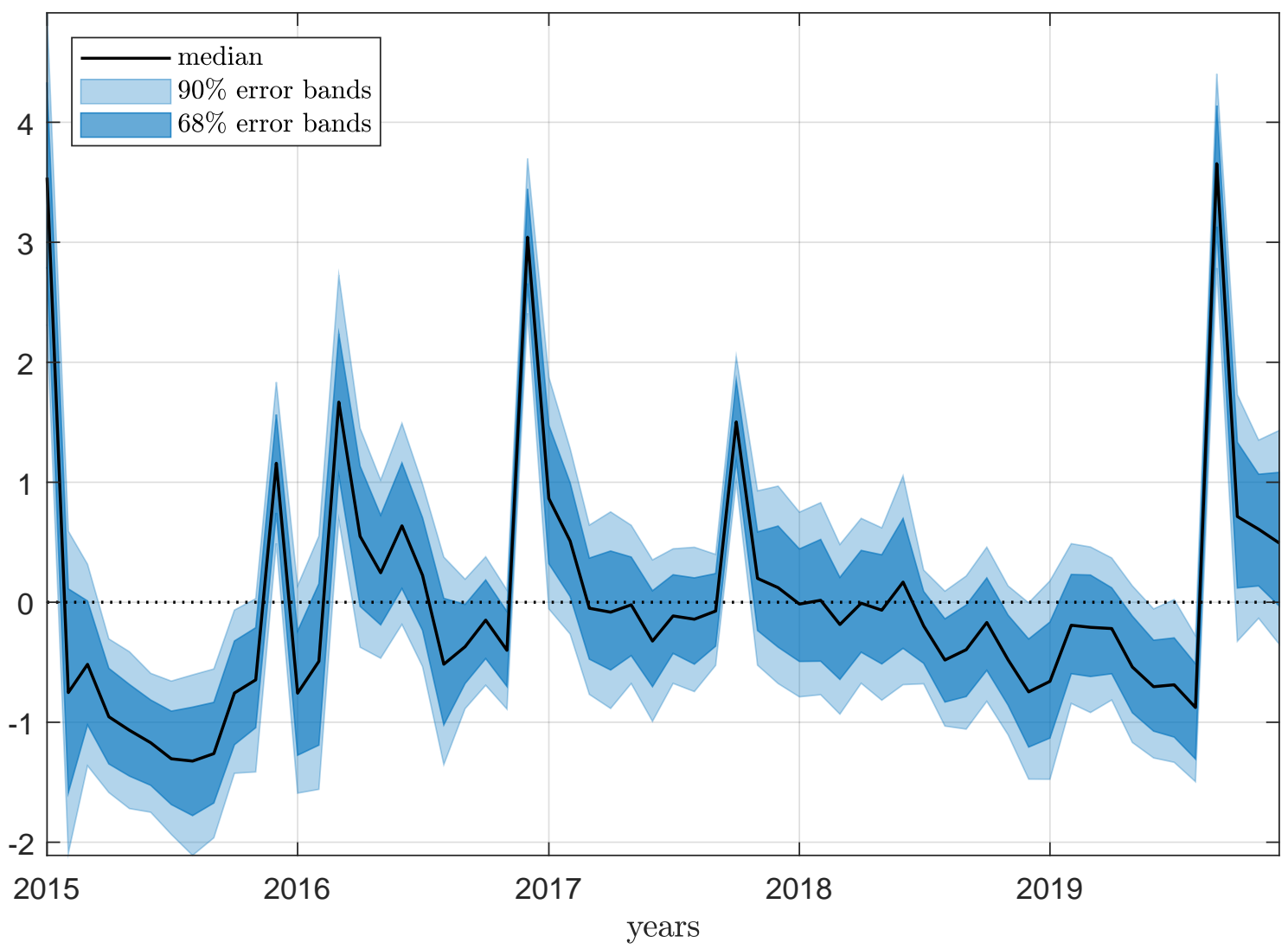

Note: Sample period: 2015.M01 - 2019.M12. Historical (median) path of structural APP shocks. The blue areas denote $68 \%$ and $90 \%$ error bands areas. 
Figure 6. Correlation between Proxy and APP Shock

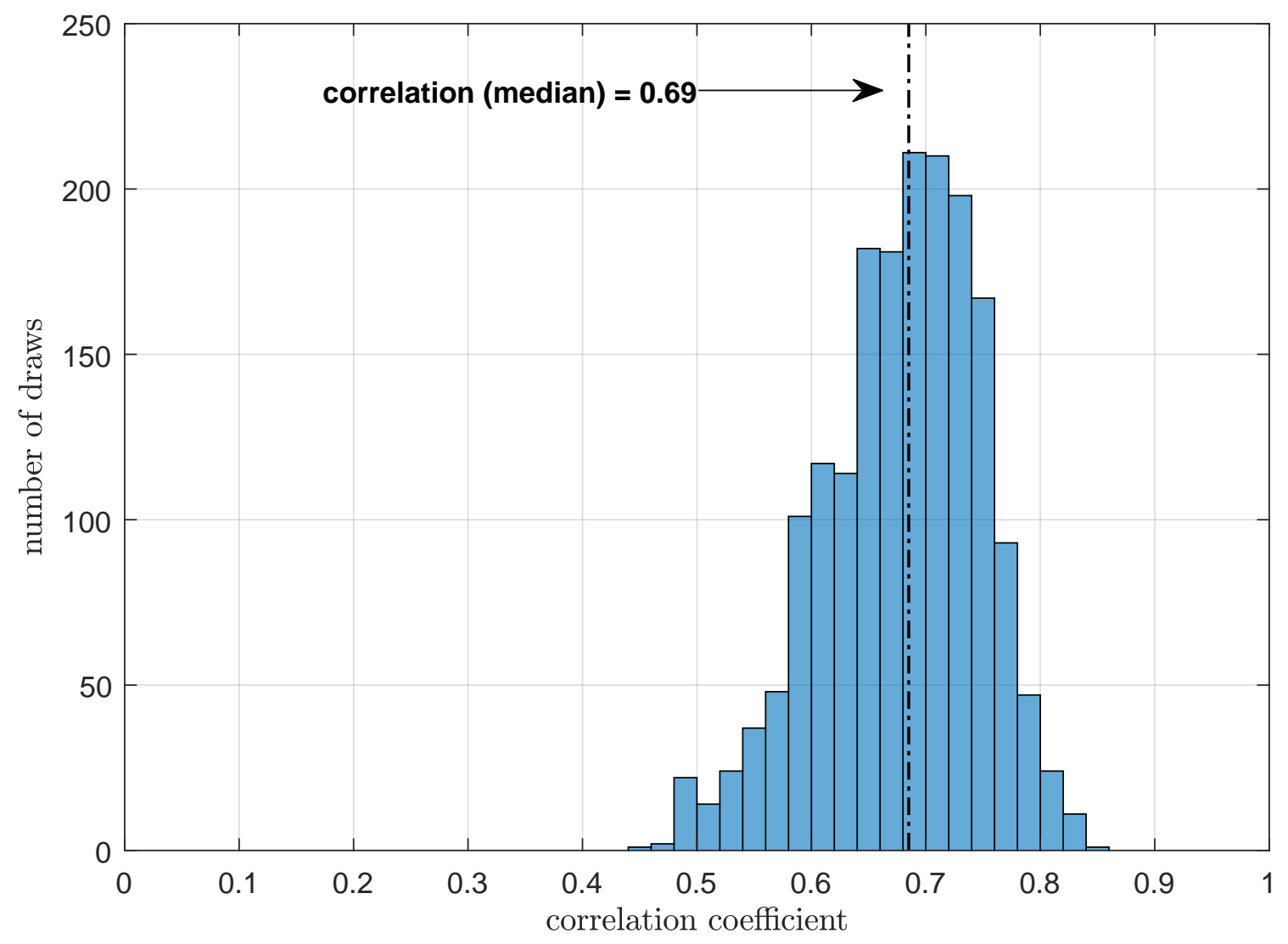

Note: Histogram based on 1805 independent draws generated from the algorithm developed by Arias, Rubio-Ramírez, and Waggoner (2018). 
FiguRE 7. Impulse responses to an APP shock
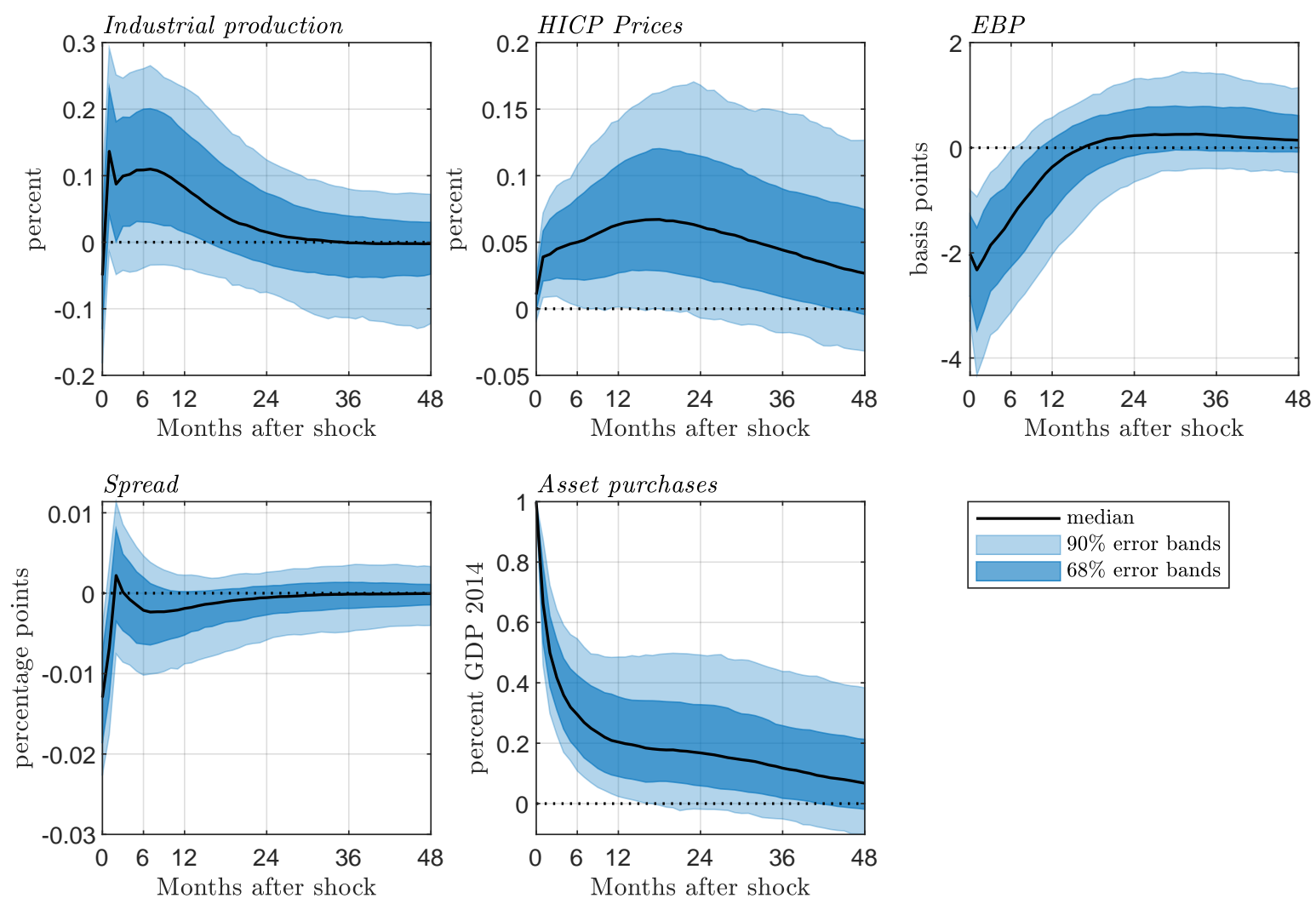

Note: The size of the shock is scaled to induce an immediate increase in asset purchases of $1 \%$ of GDP. In each panel, the median is reported in solid line, while the $68 \%$ and $90 \%$ error bands are shown by blue areas. 
Figure 8. Suppressing APP shocks.
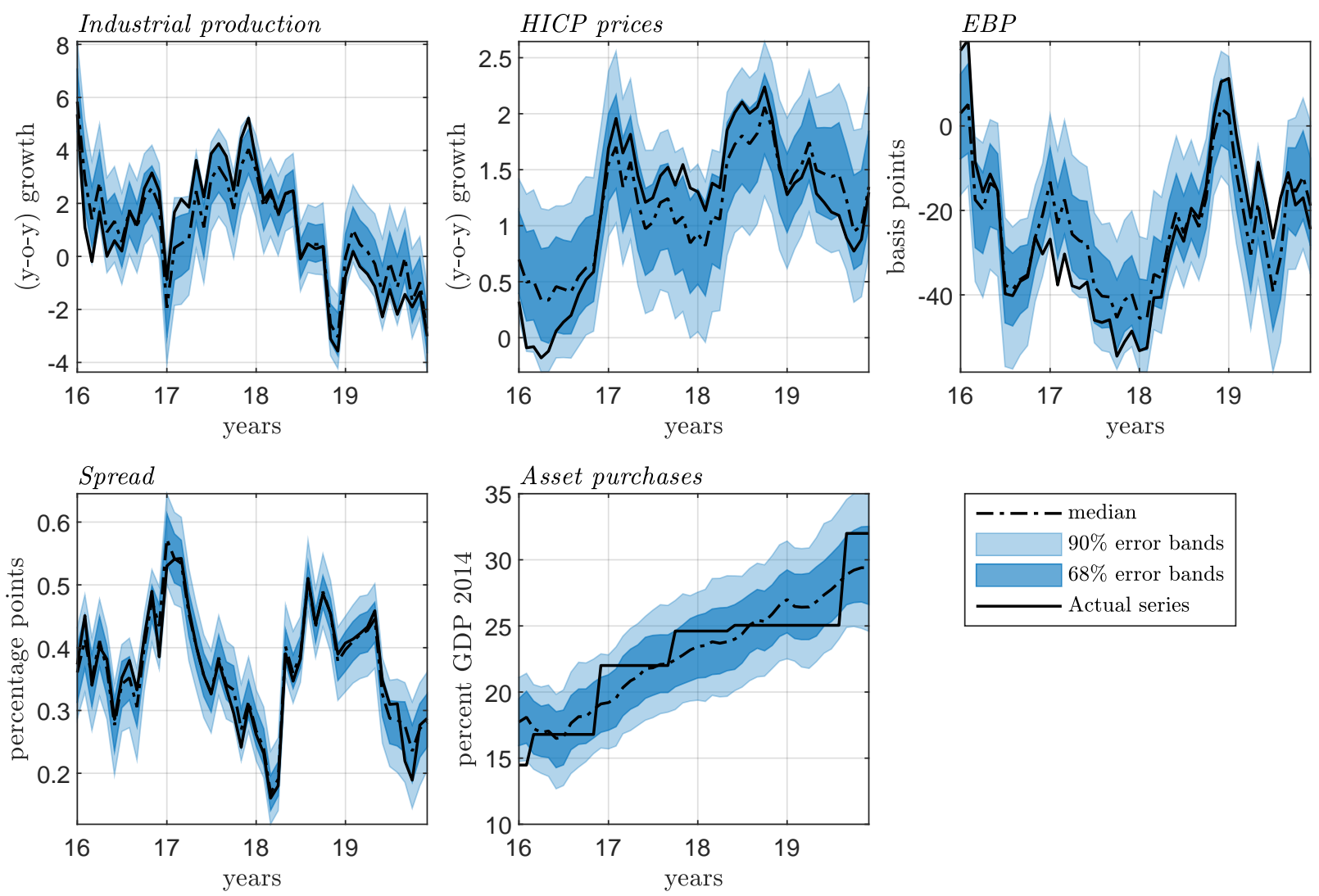

Note: Sample period: 2016.M01 — 2019.M12. Historical decomposition — i.e., suppressing APP shocks throughout the entire period. In each panel, actual and median counterfactual paths of endogenous variables are in black solid and dotted lines, respectively. The blue areas denote the counterfactual's $68 \%$ and $90 \%$ error bands areas. 
FiguRE 9. Effects of December 2015 \& March 2016 APP recalibrations.
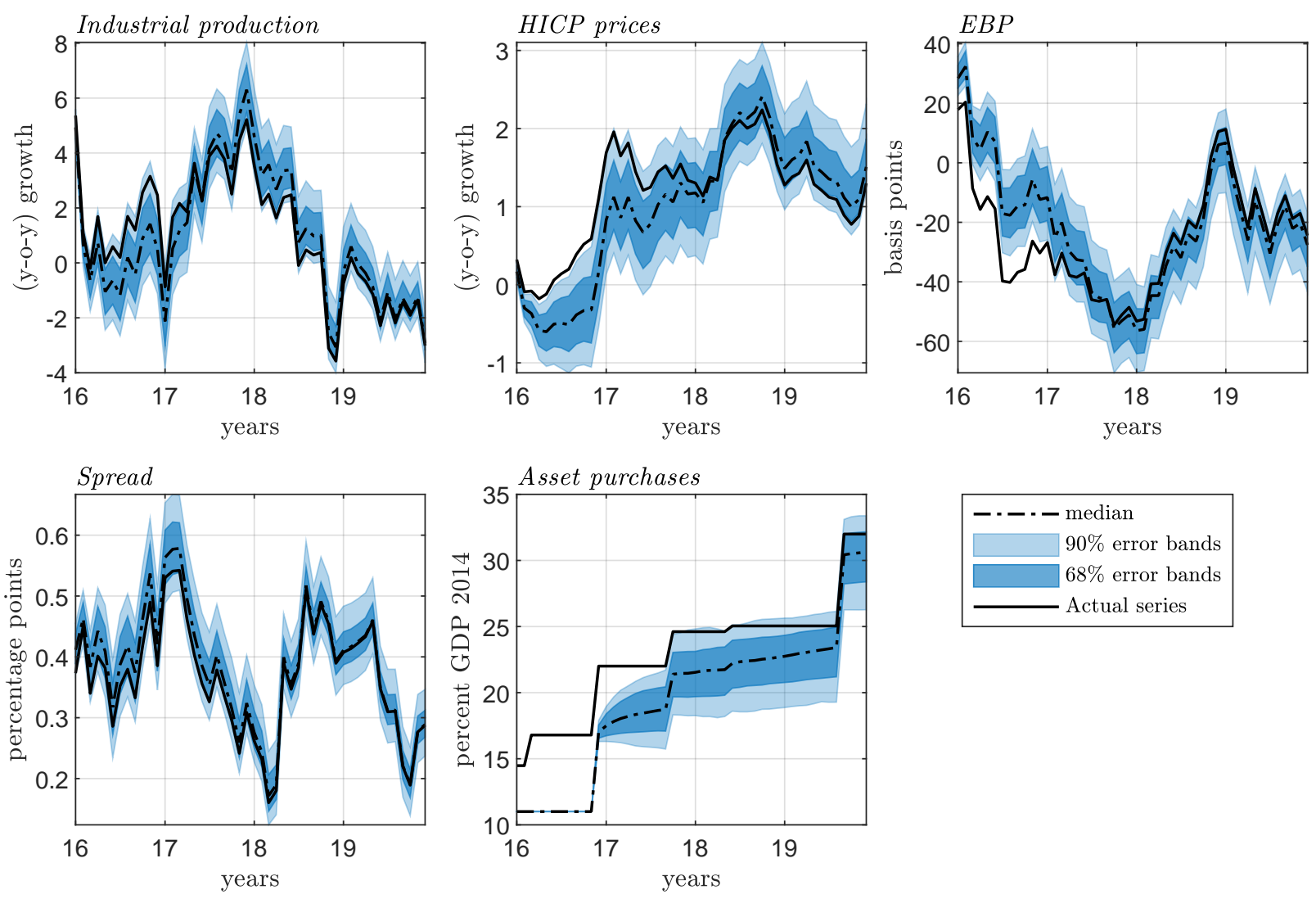

Note: Sample period: 2016.M01 - 2019.M12. Counterfactual — i.e., modifying APP shocks such that asset purchases remain unchanged from December 2015 to November 2016. In each panel, actual and median counterfactual paths of endogenous variables are in black solid and dotted lines, respectively. The blue areas denote the counterfactual's $68 \%$ and $90 \%$ error bands areas. 
FiguRe 10. Effects of December 2016 APP recalibration.
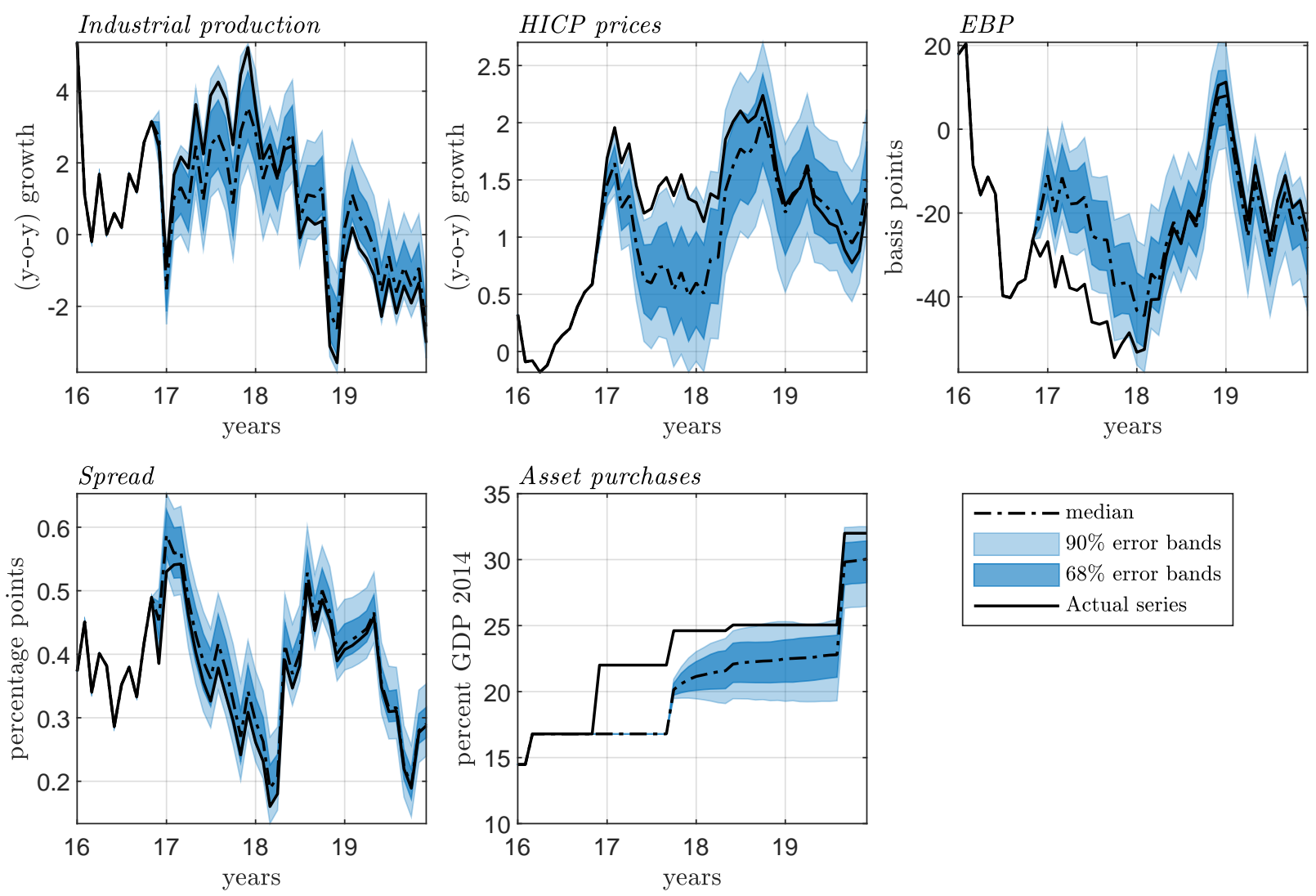

Note: Sample period: 2016.M01 — 2019.M12. Counterfactual — i.e., modifying APP shocks such that asset purchases remain unchanged from December 2016 to September 2017. In each panel, actual and median counterfactual paths of endogenous variables are in black solid and dotted lines, respectively. The blue areas denote the counterfactual's $68 \%$ and $90 \%$ error bands areas. 
FiguRE 11. Effects of October 2017 \& June 2018 APP recalibrations.
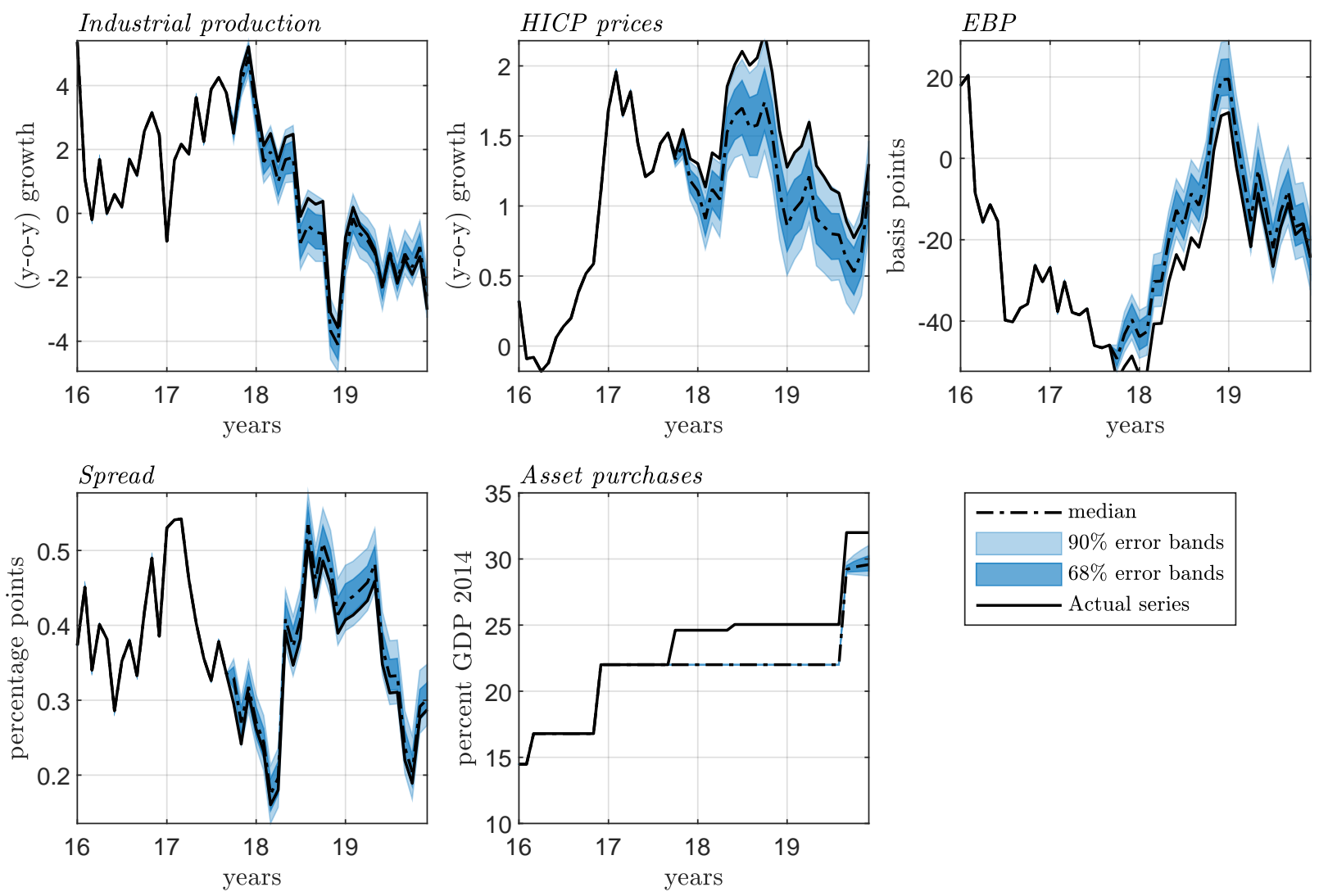

Note: Sample period: 2016.M01 - 2019.M12. Counterfactual — i.e., modifying APP shocks such that asset purchases remain unchanged from October 2017 to August 2019. In each panel, actual and median counterfactual paths of endogenous variables are in black solid and dotted lines, respectively. The blue areas denote the counterfactual's $68 \%$ and $90 \%$ error bands areas. 
Figure 12. Effects of September 2019 APP recalibration.
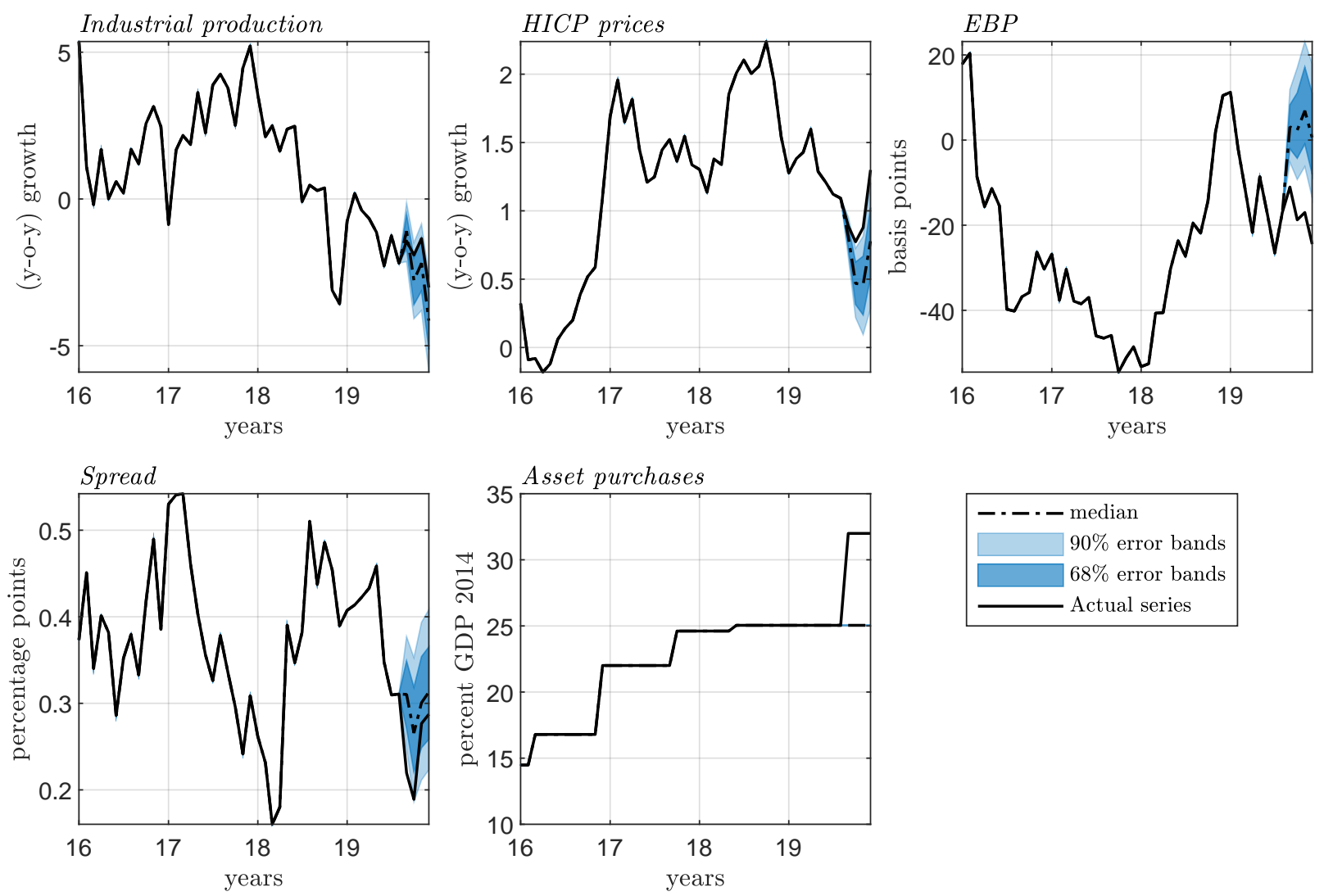

Note: Sample period: 2016.M01 — 2019.M12. Counterfactual — i.e., modifying APP shocks such that asset purchases remain unchanged from September 2019 to December 2019. In each panel, actual and median counterfactual paths of endogenous variables are in black solid and dotted lines, respectively. The blue areas denote the counterfactual's $68 \%$ and $90 \%$ error bands areas. 


\title{
ONLINE APPENDIX: THE DYNAMIC EFFECTS OF THE ECB'S ASSET PURCHASES: A SURVEY-BASED IDENTIFICATION
}

\author{
Not for Publication
}

\section{STÉPHANE LHUISSIER AND BENOÎT NGUYEN}

This Appendix consists of the following sections:
A. Data
B. Using the OIS curve to price the September 2019 APP
C. Testing for structuralness
D. Robustness Analysis
D.1. Excluding January 2015
D.2. Alternative instrument
D.3. "Internal instrument" recursive SVAR extension
E. Median peak effects of APP recalibrations.
F. Conditional and unconditional forecasts 
Appendix A. DATA

All data are organized monthly from November 2014 to December 2019. Data comes from the ECB - Statistical Data Warehouse, Reuters and Bloomberg, except for the excess bond premium which has been generously given by Roberto De Santis. Figure A.1 displays the time series data.

- $i p_{t}$ : Output is the logarithm of industrial production index, working day and seasonally adjusted.

- $p_{t}$ : Prices is the logarithm of harmonized index of consumer price (HICP), working day and seasonally adjusted.

- $a p p_{t}$ : Total size of asset purchases announced by the ECB, divided by 2014.Q1 GDP. The end-of-month value is used;

- $e b p_{t}$ : De Santis (2018a,b)'s excess bond premium (regularly updated by Roberto De Santis). The end-of-month value is used;

- $s p_{t}$ : Difference between GDP-weighted (Big4) 10-year government bond yields and the 10-year overnight index swaps (OIS). The end-of-month value is used;

Figure A.1. Time series of data (November 2014 - December 2019)
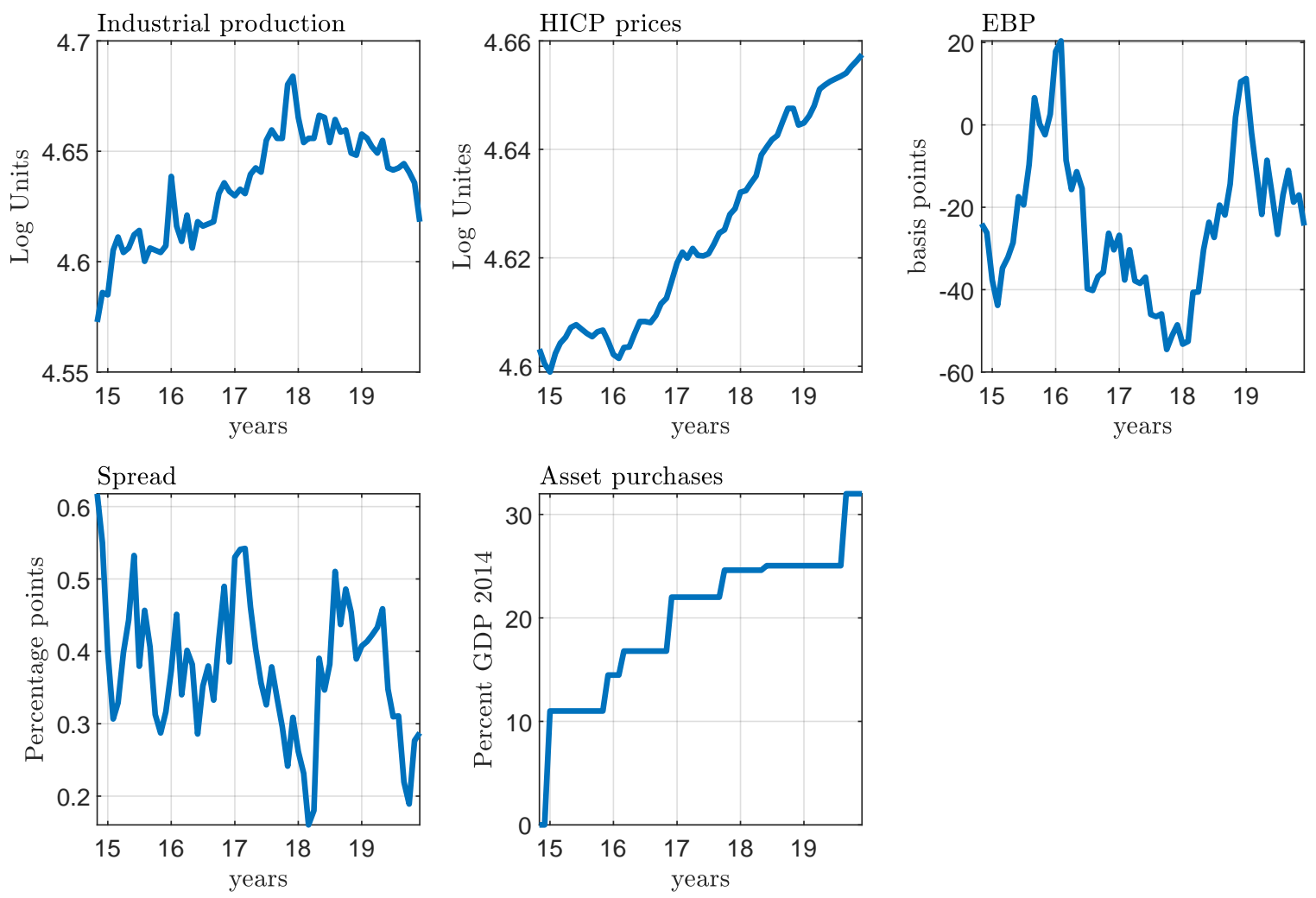


\section{Appendix B. OIS CURVE}

Results from Section V.

Figure B.1. Forward OIS curve pre-September 2019 Governing Council meeting

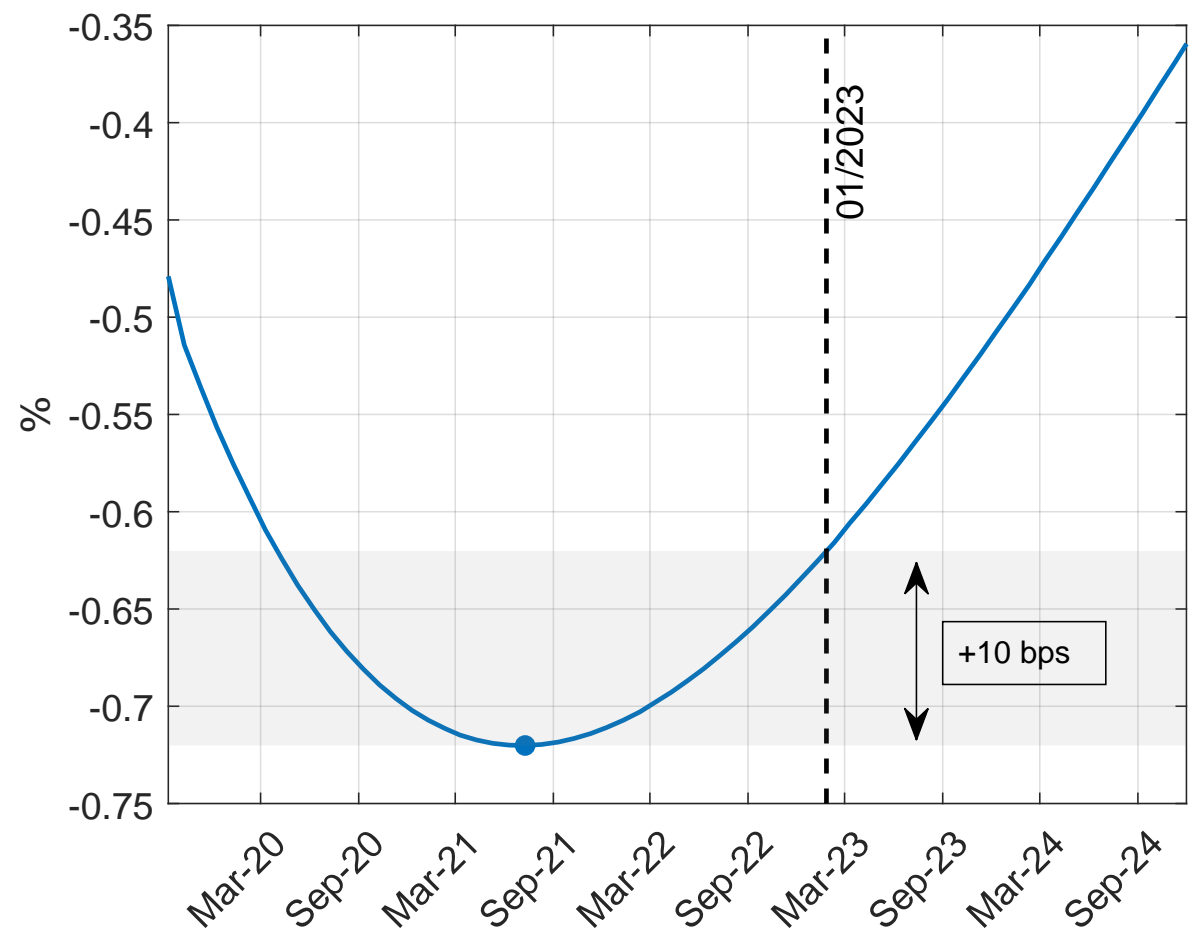

Note: Liftoff date is defined as +10 bps above the minimum reached by the OIS curve. OIS contracts from Bloomberg, as of 10-Sep-2019. We build the curve using standard Nelson Siegel procedure. 


\section{Appendix C. Testing For structuralness}

Our approach to APP identification relies on a relatively small amount of information drawn from a 5-variables Proxy-VAR. This small number of variables is unlikely to span the information sets used by the ECB, who has access to richer information about the state of the economy, or by the the financial market participants. If the information sets used in our VAR does not span that of the agents, then the structural shocks might be contaminated (i.e., non-fundamental).

In the spirit of Forni and Gambetti (2014), we perform a test of "structuralness" of the estimated APP shocks to verify whether our VAR suffers from this informational problem. To do so, we project the structural APP shocks onto the factors summarizing the information content of a large set of information available ahead of each Governing Council.

More formally, let $\varepsilon_{t}$ be the vector containing APP shocks at time $t$, and let $X_{t}$ be a vector collecting a number of macroeconomic, survey and financial variables. We define the following system:

$$
\begin{aligned}
X_{t} & =\Lambda \mathbf{f}_{t}+u_{t}, \\
\varepsilon_{t+1} & =\mathbf{f}_{t}^{\prime} B+e_{t+1},
\end{aligned}
$$

where $\mathbf{f}_{t}$ are factors summarizing the information content in $X_{t} ; u_{t}$ and $e_{t}$ are independent identically distributed (i.i.d) shocks; and $B$ is the matrix that loads factors onto structural APP shocks. if $B$ is statistically significant, then shocks can be predicted using past common information, meaning that they are not structural. Following Andrade and Ferroni (2020), we consider a set of 38 variables in $X_{t}$ that are related to macroeconomic, survey and financial time series. The list of variables is reported in Table C.1. We then extract their principal components using the factor extraction technique developed by Bai and Ng (2002). The number of factors is equal to 5 . We then regress APP shocks on these factors and look at their statistical significance.

Table C.2 reports the individual p-values of the coefficients of the regression of APP shocks on lagged factors. Clearly, APP shocks are not predictable by the available information ahead of each Governing Council. 
TABle C.1. List of variables included in $X_{t}$ to test the predicability of APP shocks. Transformations: $1=$ first difference; $2=$ growth rate.

\begin{tabular}{|c|c|c|}
\hline Variables & Code Series (ECB SDW) & Transf \\
\hline Adjusted loans to euro area private sector & BSI.M.U2.Y.U.A20TA.A.1.U2.2200.Z01.E & 2 \\
\hline Monetary aggregate M3 & BSI.M.U2.Y.V.M30.X.1.U2.2300.Z01.E & 2 \\
\hline Japanese yen/Euro & EXR.M.JPY.EUR.SP00.A & 1 \\
\hline Unemployment rate (as a \% of labour force) & STS.M.I8.S.UNEH.RTT000.4.000 & 1 \\
\hline Euribor 3-month & FM.M.U2.EUR.RT.MM.EURIBOR3MD_.HSTA & 1 \\
\hline EER-42/Euro & EXR.M.E7.EUR.EN00.A & 1 \\
\hline CPI deflated EER-42/Euro & EXR.M.E7.EUR.ERC0.A & 1 \\
\hline Dow Jones Euro Stoxx 50 Price Index & FM.M.U2.EUR.DS.EI.DJES50I.HSTA & 2 \\
\hline Standard and Poors 500 Composite Index & FM.M.US.USD.DS.EI.S_PCOMP.HSTA & 2 \\
\hline HICP - Overall index & ICP.M.U2.Y.000000.3.INX & 2 \\
\hline ECB Commodity Price index & STS.M.I8.N.UWIE.CTOTNE.3.000 & 2 \\
\hline Unemployment rate, Male & STS.M.I8.S.UNEH.RTM000.4.000 & 1 \\
\hline New passenger car registration & STS.M.I8.Y.CREG.PC0000.3.ABS & 2 \\
\hline Industrial new orders; total & STS.M.I8.Y.ORDT.NSC002.3.000 & 2 \\
\hline Industrial production for the euro area & STS.M.I8.Y.PROD.NS0020.4.000 & 2 \\
\hline Industrial production; intermediate goods & STS.M.I8.Y.PROD.NS0040.4.000 & 2 \\
\hline Industrial production; consumer goods & STS.M.I8.Y.PROD.NS0080.4.000 & 2 \\
\hline Industrial production; energy & STS.M.I8.Y.PROD.NS0090.4.000 & 2 \\
\hline Industrial production; including construction & STS.M.I8.Y.PROD.NS0010.4.000 & 2 \\
\hline Industrial production; excl. construction, energy & STS.M.I8.Y.PROD.NS0021.4.000 & 2 \\
\hline Industrial production; durable consumer goods & STS.M.I8.Y.PROD.NS0060.4.000 & 2 \\
\hline Industrial turnover, nominal; manufacturing & STS.M.I8.Y.TOVT.2C0000.4.000 & 2 \\
\hline Retail trade turnover & STS.M.I8.Y.TOVT.NS4701.4.000 & 2 \\
\hline UK pound sterling/Euro & EXR.D.GBP.EUR.SP00.A & 1 \\
\hline EONIA & EON.D.EONIA_TO.RATE & 1 \\
\hline US dollar/Euro & EXR.D.USD.EUR.SP00.A & 1 \\
\hline HICP; excluding energy and unprocessed food & ICP.M.U2.Y.XEFUN0.3.INX & 2 \\
\hline Euribor 1-year & RTD.M.S0.N.C_EUR1Y.E & 1 \\
\hline Brent crude oil 1-month Forward & RTD.M.S0.N.P_OILBR.E & 2 \\
\hline Consumer Confidence Indicator & RTD.M.SO.S.Y_CSCCI.F & 2 \\
\hline Economic Sentiment Indicator & RTD.M.SO.S.Y_ESIND.F & 2 \\
\hline U.S. Consumer Price Index & CPIAUCSL (FED FRED) & 2 \\
\hline U.S. all Employees, Total Nonfarm & PAYEMS (FED FRED) & 2 \\
\hline U.S. 10-Year Treasury Constant Maturity Rate & DGS10 (FED FRED) & 1 \\
\hline U.S. Advance Real Retail and Food Services Sales & RRSFS (FED FRED) & 2 \\
\hline U.S. 3-Month Treasury Bill & TB3MS (FED FRED) & 1 \\
\hline U.S. Unemployment Rate & UNRATE (FED FRED) & 1 \\
\hline U.S. ISM Manufacturing PMI & NAPMPMI Index (Bloomberg) & 2 \\
\hline
\end{tabular}


TABle C.2. Predictability of structural APP shocks

\begin{tabular}{lc}
\hline \hline Factors in set of 38 variables & APP shocks \\
\hline$f_{1}$ & 0.95 \\
$f_{2}$ & 0.69 \\
$f_{3}$ & 0.75 \\
$f_{4}$ & 0.46 \\
$f_{5}$ & 0.95 \\
\hline
\end{tabular}

Note: P-values of the regression of APP shocks on macroeconomic, survey, and financial lagged factors. 


\section{Appendix D. Robustness Analysis}

D.1. Excluding January 2015. Results from Section VI.5.1.

Figure D.1. Excluding January 2015 from the sample
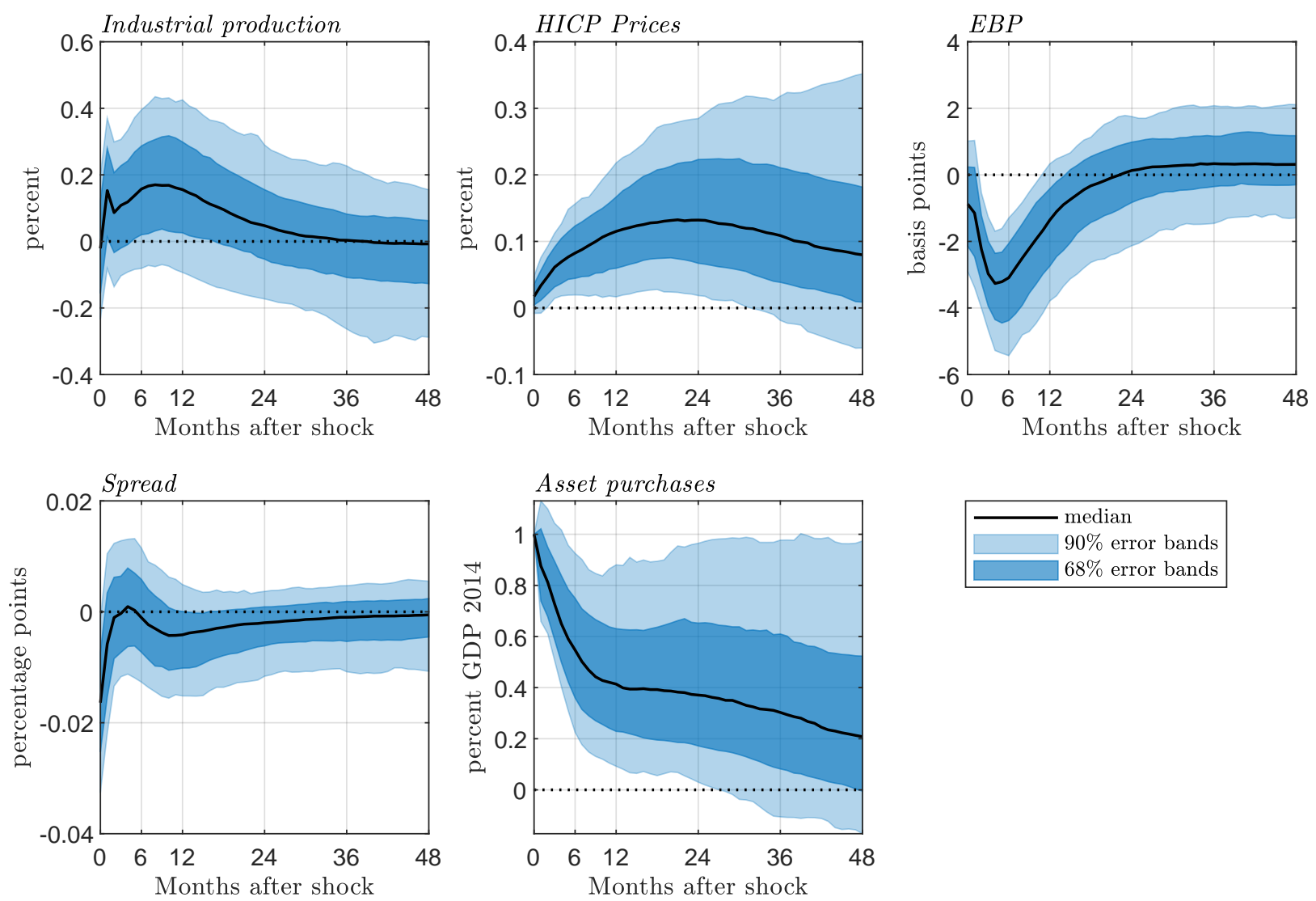

Note: The size of the shock is scaled to induce an immediate increase in asset purchases of $1 \%$ of GDP. In each panel, the median is reported in solid line, while the $68 \%$ and $90 \%$ error bands are shown by blue areas. 
D.2. Alternative Instrument. Results from Section VI.5.2.

Figure D.2. Baseline Proxy versus Reweighted Proxy around Governing Council Announcements.

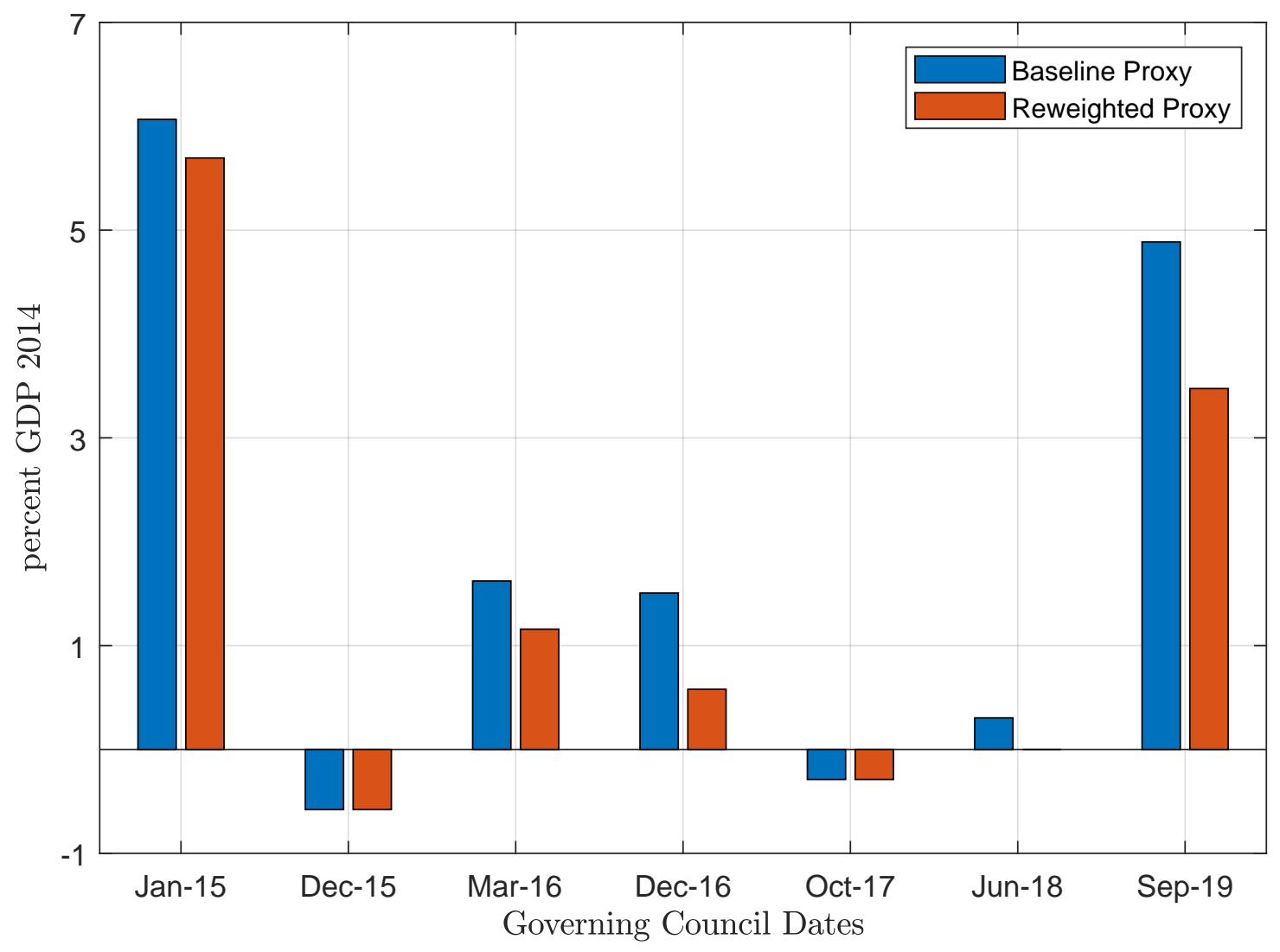

Note: Unexpected components are scaled to GDP 2014. Our baseline measure of surprises takes into account the fact that a proportion of respondents were not expected the announcement of a new APP recalibration at the upcoming GovC. Their expectations were then set to zero. The reweighted proxy recompute the surprises using only the answers by the respondents who expected an APP recalibration at the next Governing Council. 
Figure D.3. Impulse responses to an APP shock
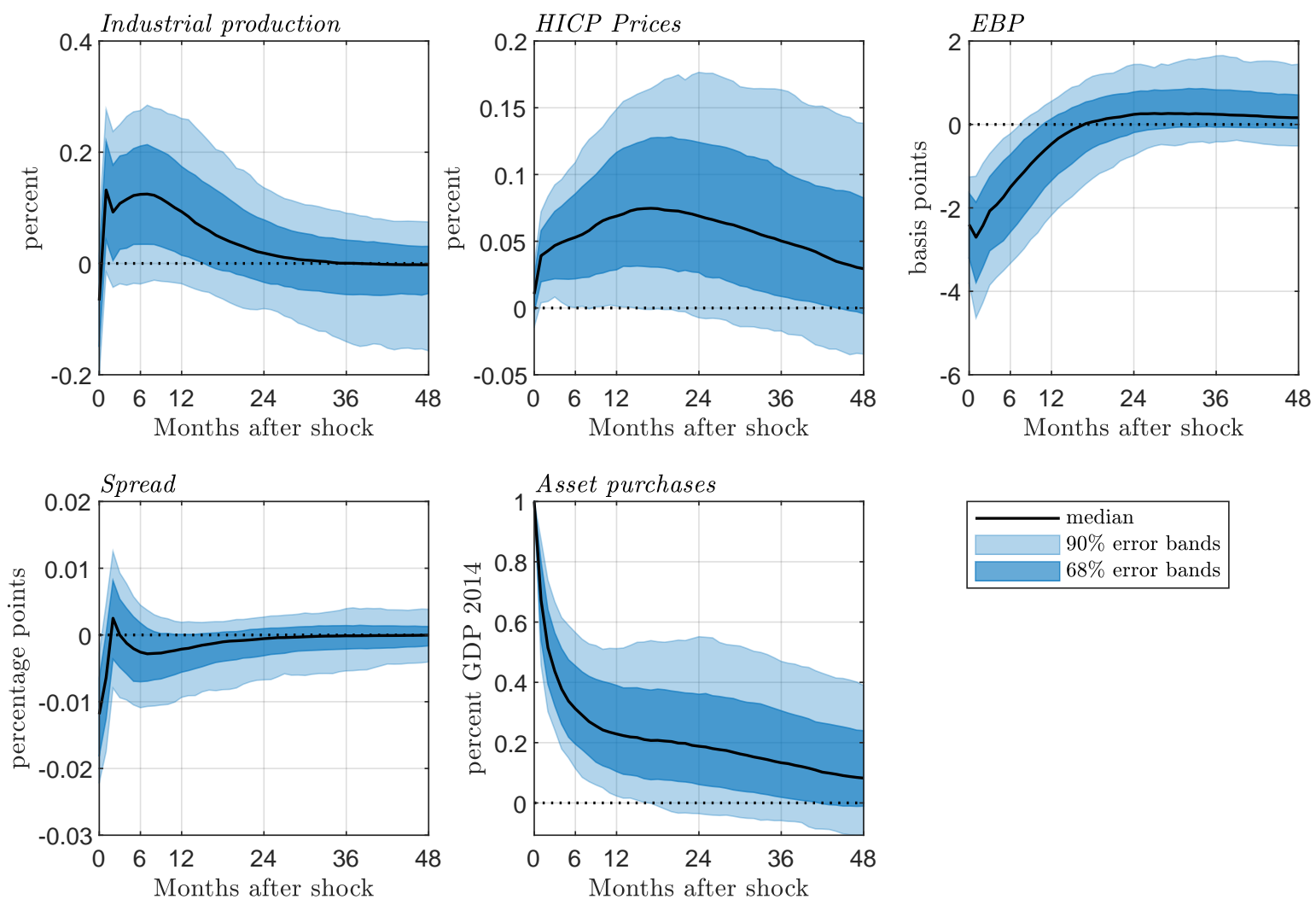

Note: The size of the shock is scaled to induce an immediate increase in asset purchases of $1 \%$ of GDP. In each panel, the median is reported in solid line, while the $68 \%$ and $90 \%$ error bands are shown by blue areas. 


\section{D.3. "Internal instrument" recursive SVAR. Results from Section VI.5.3.}

Figure D.4. Impulse responses to an APP shock using an "Internal instrument" approach
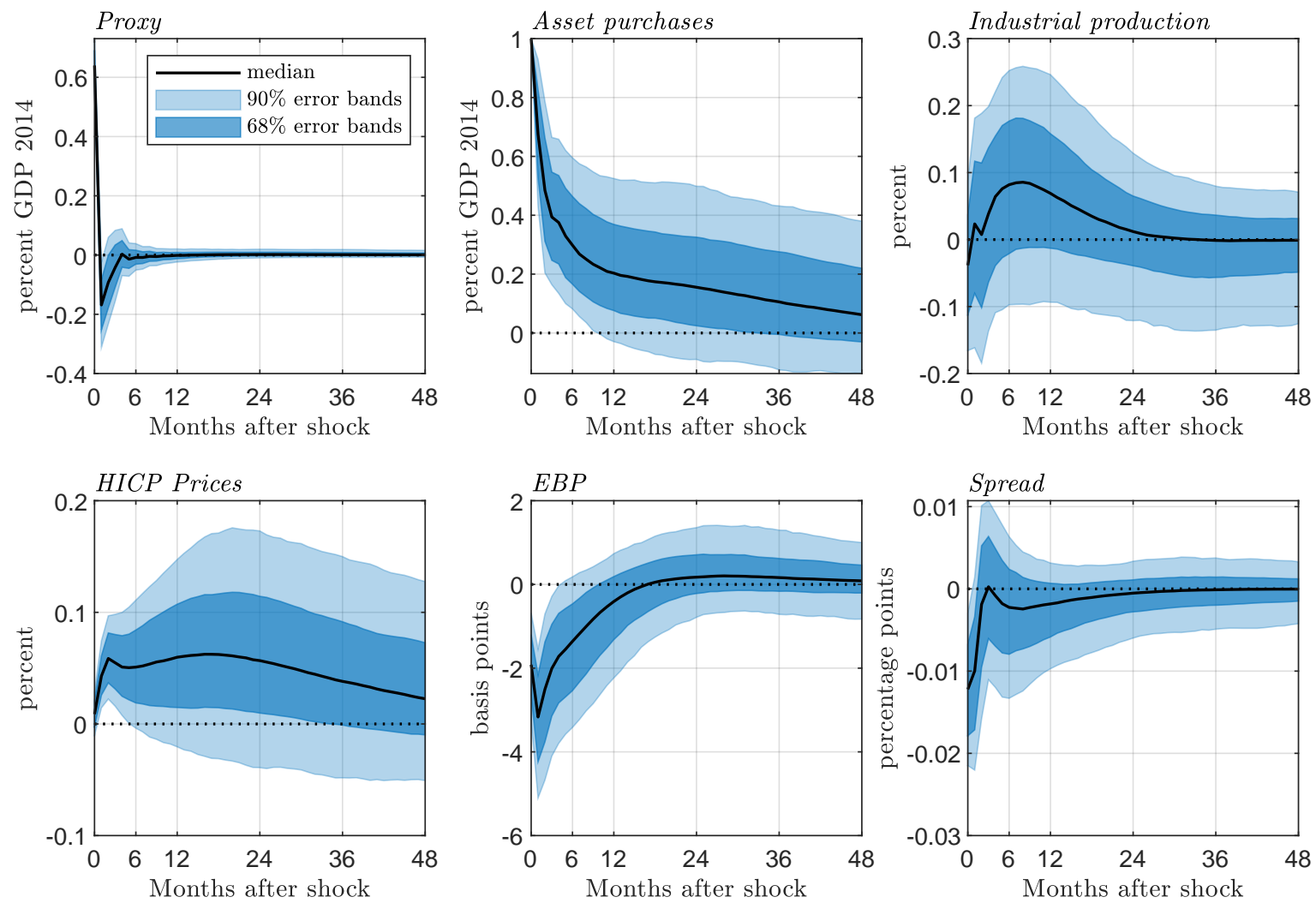

Note: The size of the shock is scaled to induce an immediate increase in asset purchases of $1 \%$ of GDP. In each panel, the median is reported in solid line, while the $68 \%$ and $90 \%$ error bands are shown by blue areas. 
Appendix E. Median Peak Effects

Figure E.1. Peak effect of APP recalibration rounds
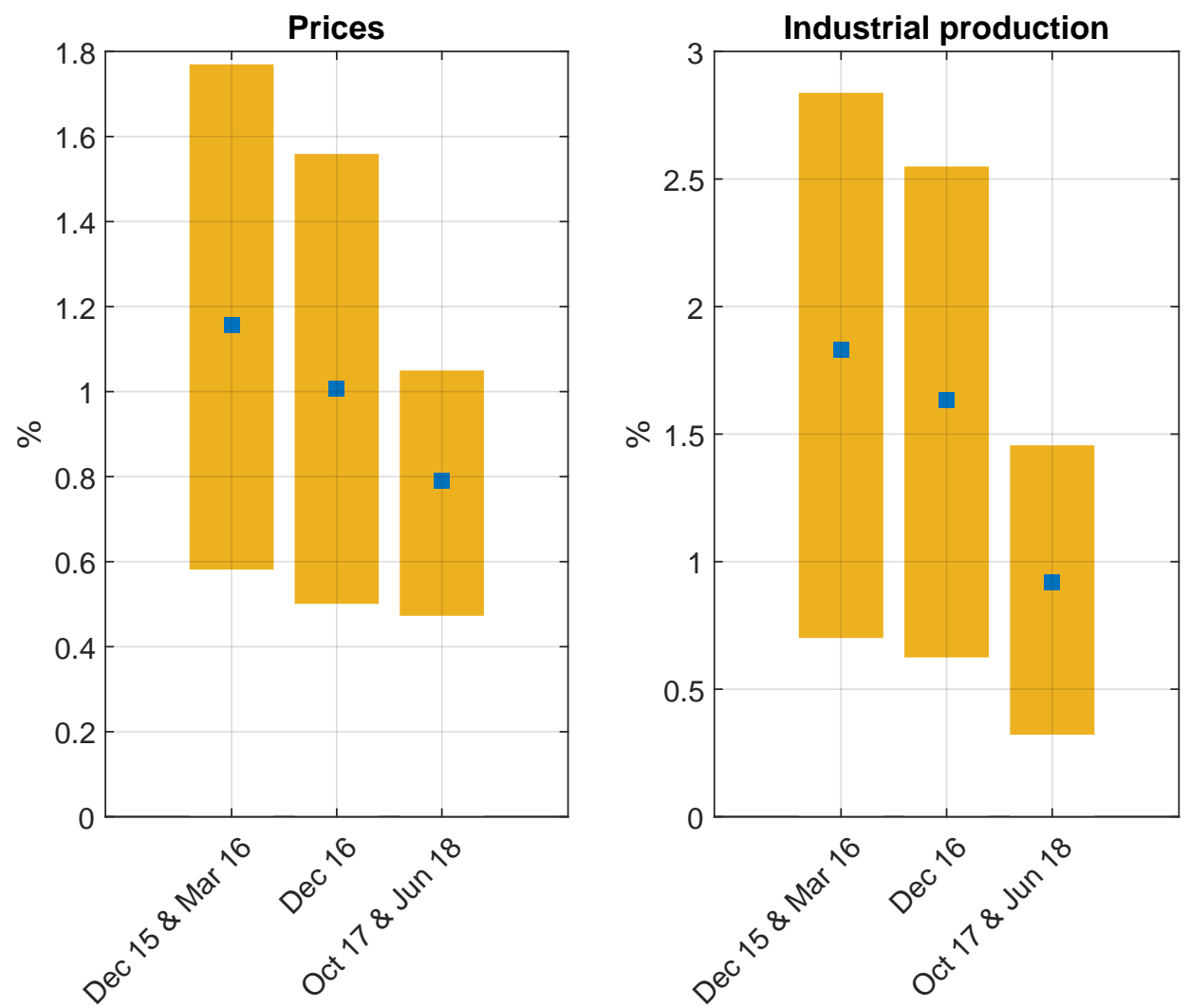

Note: Blue squares denote the median and yellow bars the $68 \%$ uncertainty bands. Sep 2019 recalibration not shown as its full impact may not be reflected in our sample ending in Dec 2019. 
FiguRE E.2. Peak effect of APP recalibration rounds - rescaled for $1 \%$ of euro area GDP.
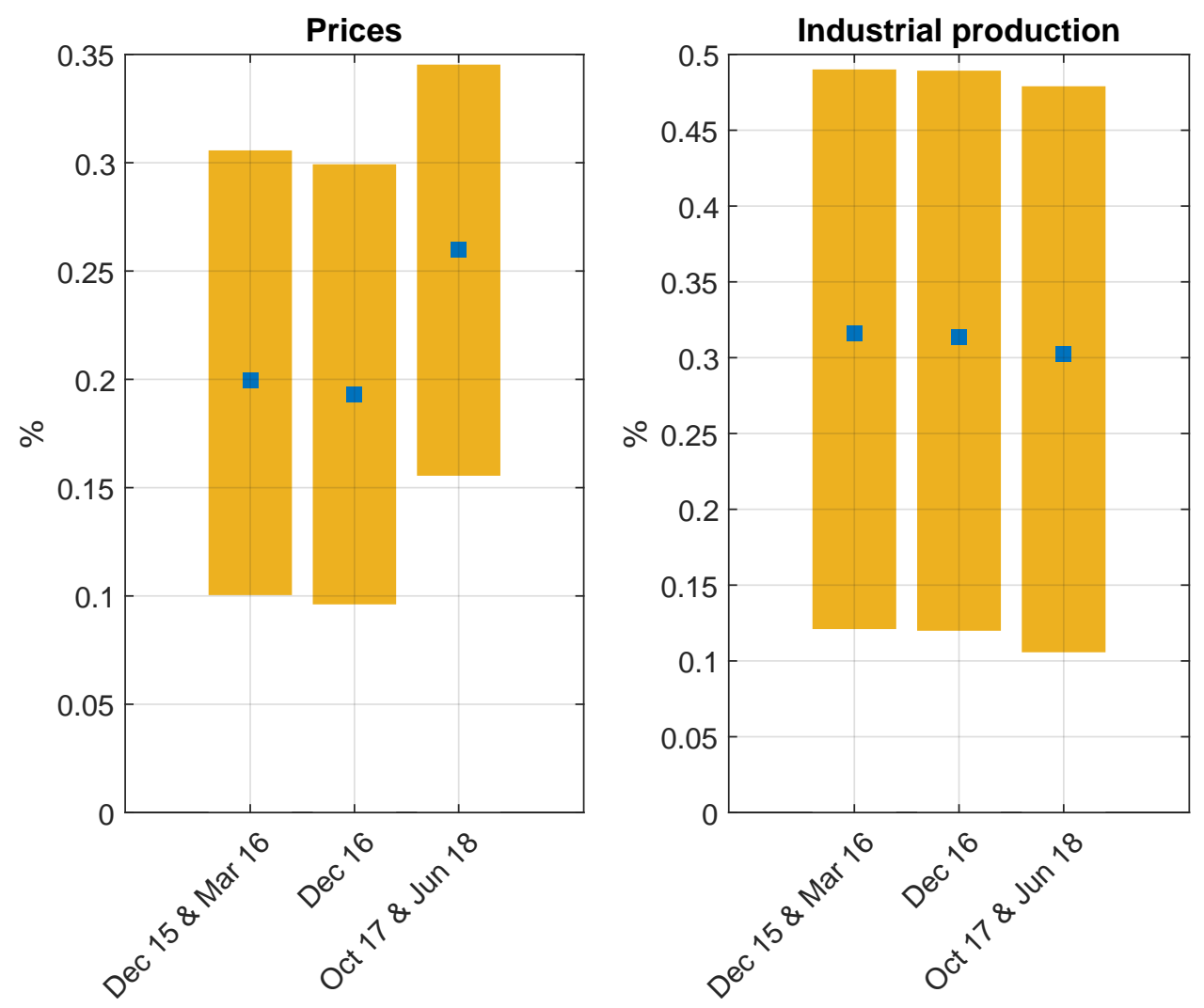

Note: Blue squares denote the median and yellow bars the $68 \%$ uncertainty bands. We rescale each recalibration round by 2014Q1 euro area GDP. Sep 2019 recalibration not shown as its full impact may not be reflected in our sample ending in Dec 2019. 


\section{Appendix F. Conditional versus Unconditional Forecasting}

Figure F.1. Conditional versus Unconditional Forecasts.
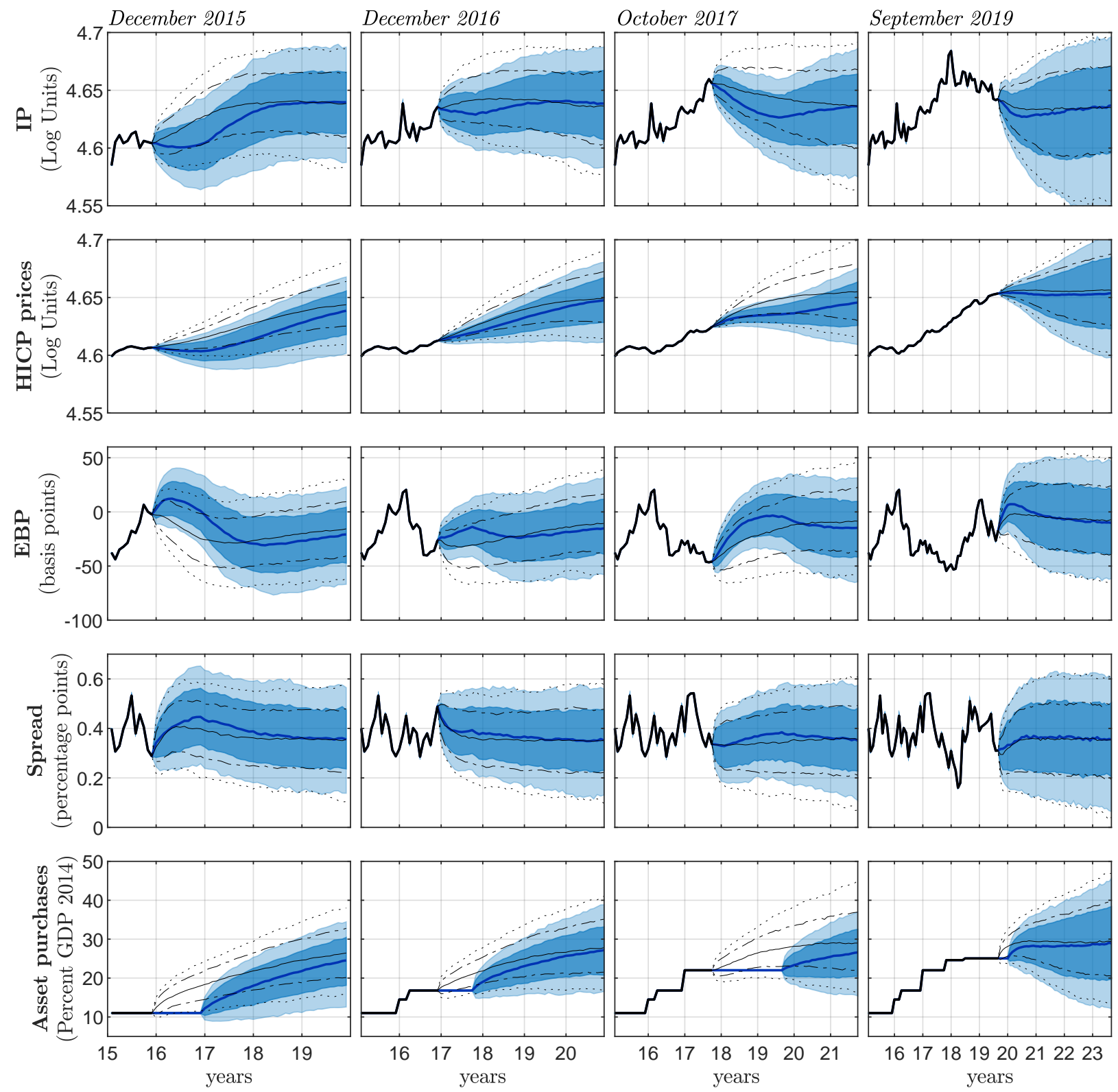

Note: Each column represents the conditional and unconditional forecasts starting at different periods: December 2015, December 2016, October 2017, and September 2019. The median of conditional forecasts is reported in solid blue line with $68 \%$ and $90 \%$ error bands in blue areas. The median of unconditional forecasts is reported in solid black line, along with $68 \%$ and $90 \%$ error bands in dotted lines. 